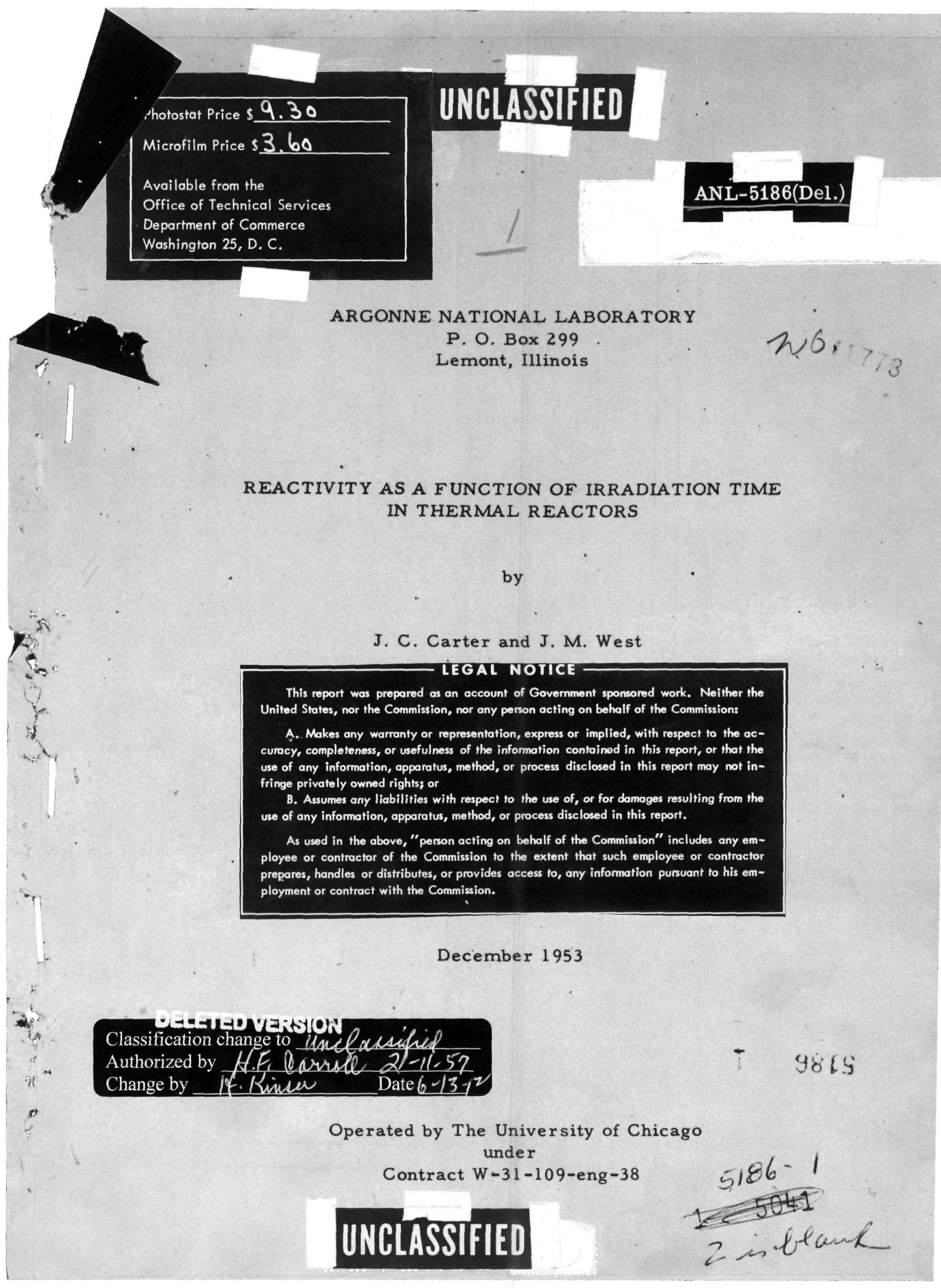




\section{DISCLAIMER}

This report was prepared as an account of work sponsored by an agency of the United States Government. Neither the United States Government nor any agency Thereof, nor any of their employees, makes any warranty, express or implied, or assumes any legal liability or responsibility for the accuracy, completeness, or usefulness of any information, apparatus, product, or process disclosed, or represents that its use would not infringe privately owned rights. Reference herein to any specific commercial product, process, or service by trade name, trademark, manufacturer, or otherwise does not necessarily constitute or imply its endorsement, recommendation, or favoring by the United States Government or any agency thereof. The views and opinions of authors expressed herein do not necessarily state or reflect those of the United States Government or any agency thereof. 


\section{DISCLAIMER}

Portions of this document may be illegible in electronic image products. Images are produced from the best available original document. 


\section{TABLE OF CONTENTS}
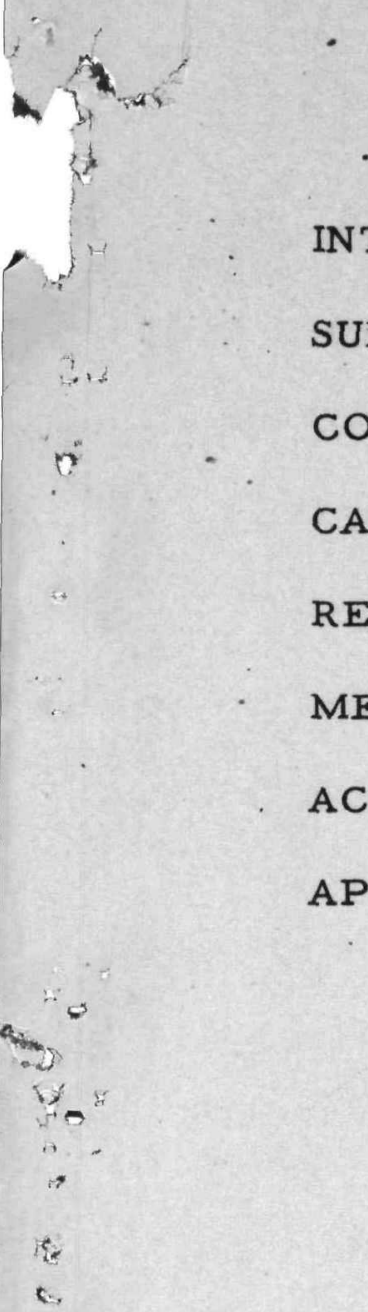

Page

INTRODUCTION $\ldots \ldots \ldots \ldots \ldots \ldots \ldots \ldots \ldots \ldots \ldots \ldots \ldots \ldots \ldots \ldots \ldots \ldots$

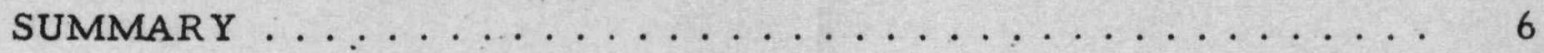

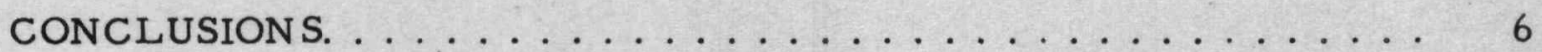

CALCULATION METHODS ..................

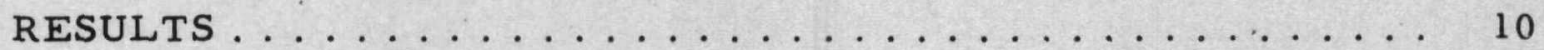

METHODS OF MAINTAINING REACTIVITY $\ldots \ldots \ldots \ldots \ldots \ldots$

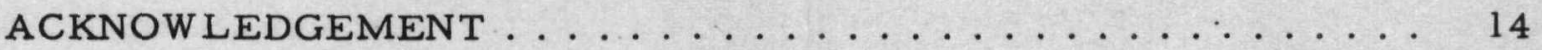

APPENDIX I - Nuclear Constants ............... 15 


\section{LIST OF FIGURES}

Fig. No.

Title

Page

I

II

III

IV $a-j$

V

VI

VII

VIII

IX a

IX b

IX c

IX d

$\mathrm{X}$

$\mathrm{XI}$

Diagram of the Uranium-Plutonium Reaction. . . . . . 16

Equations of Isotopic Abundance in the UraniumPlutonium Reaction .................... 17

Effect of Increasing the Cross Section of $\mathrm{Pu}^{239}$ by

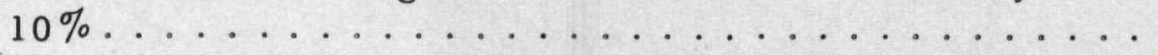
$\mathrm{Pu}^{241}$

Variation of Reactivity vs. Irradiation Time for Natural Uranium . . . . . . . . . . . . . . .

The Average Variation of Reactivity vs. Irradiation Time for Natural Uranium. . . . . . . . . . . .

Reactivity Limitations of Fuel Irradiation in Natural Uranium Heavy Water Reactors with Incremental Reloading of

$\eta$ vs. Ir radiation with Enrichment as Parameter . . . .

Reactivity Variations with Irradiation Time for a $\mathrm{D}_{2} \mathrm{O}$ Boiling, Light Water, and Sodium Graphite

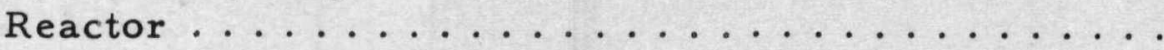

Variations of " $\eta$ " with Irradiation Time for a $\mathrm{D}_{2} \mathrm{O}$ Boiling, Light Water Boiling and Sodium Graphite

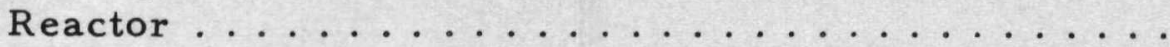

Variation of " $f$ " with Irradiation for a $D_{2} \mathrm{O}$ Boiling, Light Water Boiling, and Sodium Graphite Reactor. . . .

Average Reactivity Variation with Irradiation Time for a $\mathrm{D}_{2} \mathrm{O}$ Boiling, Light Water Boiling, and Sodium Graphite Reactor ...................

The Effect of Enrichment upon the $\mathrm{Pu}^{240} / \mathrm{Pu}^{239}$ Ratio for Constant Power Reactors ..............

The Effect upon Reactivity of Removing Fuel During the Operation of a Natural Uranium Reactor ........ 


\title{
REACTIVITY AS A FUNCTION OF IRRADIATION TIME IN THERMAL REACTORS
}

\author{
by
}

J. C. Carter and J. M. West

\section{INTRODUCTION}

This report is concerned with a theoretical investigation of reactivity variation as a function of irradiation time in thermal reactors which use depleted, natural, or slightly enriched uranium as fuel.

In all thermal reactors it is desirable to irradiate the uranium fuel as long as possible, consistent with other requirements. This is due to the fact that the cost of fuel, fuel fabrication, and, in some cases, fuel processing, per unit of saleable product decreases as the lifetime of the fuel increases. This lifetime is normally limited by one of the following:

1. The fuel in plutonium producers must be discharged when the ratio of $\mathrm{Pu}^{240}$ to $\mathrm{Pu}^{239}$ reaches a maximum value determined by military requirements.

2. The fuel must be replaced in a power reactor when the reactivity of the reactor drops below unity due to progressive changes in isotopic composition of the fuel.

3. If not limited by 1 or 2 , the fuel can be irradiated until it becomes damaged by pile radiations and fission products to such an extent that the reactor cannot operate efficiently and safely:

To estimate how long the fuel in a plutonium or power producing reactor can operate before reaching limits 1 or 2 , it is necessary to know the isotopic content of the fuel as a function of time. Since the equations governing isotopic changes are rather complicated it is necessary to resort to computing machines in order to get rigorous solutions with comprehensive coverage of the range of variables in a reasonable length of time. This report presents the solutions of these equations obtained by use of a Reeves Electronic Analog Computer (REAC) for thermal reactors having a wide range of enrichments and conversion ratios. Sample calculations showing how these isotope curves are used to calculate reactivity as a function of time for certain reactors of greatest current interest are included.

The writers are conscious of the fact that the results obtained in this investigation can be no better than the nuclear constants used. When better constants for plutonium isotopes and fission products become available, a review and extension of this study will be in order. 


\section{SUMMARY}

Equations governing the variation of $\mathrm{U}^{235}, \mathrm{U}^{238}, \mathrm{Pu}^{239}, \mathrm{Pu}^{240}$, and $\mathrm{Pu}^{241}$ have been derived and their solutions plotted as a function of irradiation time. The initial $U^{235}$ content of the uranium was varied from $0.5 \%$ to $2.0 \%$. The range of conversion ratios was from 0.5 to 1.2 . The irradiation was from 0 to $20,000 \mathrm{mwd} / \mathrm{ton}$ of fuel.

Since a range of initial conversion ratios is associated with each value of enrichment, a solution results in a family of curves for each isotope, and, since the range of enrichments is large, the number of curves (Figures IVa to IVj) is quite large.

Translation of the isotope curves to reactivity variation necessitates a calculation requiring a modest amount of time for a particular case but a prohibitive amount of time to cover the entire range of possible combinations of enrichment and initial conversion ratios. Reactivity variation as a function of irradiation time has been computed for a natural uranium reactor with an initial conversion ratio ranging from 0.7 to 1.2 and for 3 types of reactors in which there is considerable current interest. Similar. calculations for other reactors can be made by making use of the isotope curves and the calculation t.echnique set forth in this report.

\section{CONCLUSIONS}

1. The most important factor involved in maintaining adequate reactivity over a long period of time is the initial conversion ratio. An initial conversion ratio of 1.2 in a natural uranium reactor would enable the reactor to operate for $20,000 \mathrm{mwd} /$ ton with a loss of less than $1-1 / 2 \% \mathrm{re}-$ activity, (Figure V). As the conversion ratio decreases (the initial enrichment remaining the same), the loss in reactivity becomes more pronounced. At an initial conversion ratio of 0.9 a loss of $11 \%$ in reactivity is reached at $10,000 \mathrm{mwd} / \mathrm{ton}$.

2. For a given conversion ratio, the reactivity loss increases with enrichment. The reactivity loss is not excessive with an increase in enrichment if the conversion ratio is high. The reactivity as a function of time is dependent upon the motive for the enrichment. If the enrichment were necessary because of large parasitic capture or leakage of neutrons (low initial conversion ratio) the loss in reactivity would be rapid. If, on the other hand, the enrichment were an arbitrary move to allow greater subdivision of the fuel (high resonance capture of neutrons and, therefore, no loss in initial conversion ratio) the reactivity loss per unit of heat liberated in an enriched reactor would not be very much greater than in a natural uranium reactor with the same conversion ratio. 
3. For fuel with low $U^{235}$ content, the reactivity increases initially and later declines steadily. As enrichment increases, the amplitude of the initial surge diminishes until an enrichment is reached above which the reactivity declines from the initiation of the irradiation.

4. The ratio of $\mathrm{Pu}^{240}$ to $\mathrm{Pu}^{239}$, in a constant power reactor, at any time during the irradiation varies approximately inversely as the initial enrichment of the fuel. In the case of plutonium producers, this is significant in that the more enriched the uranium the longer it can be kept in the reactor before the limiting ratio of $\mathrm{Pu}^{240}$ to $\mathrm{Pu}^{239}$ is reached.

5. The character of reactivity vs. irradiation time curves is largely determined by the character of " $\eta$," as the variation in " $f$ " for the cases considered is relatively small.

6. For equal values of initial conversion ratio the curves of " $\eta$ " vs. irradiation with enrichment as parameter, tend to converge with prolonged irradiation $(10,000$ to $20,000 \mathrm{mwd} / \mathrm{ton})$.

7. The Reeves Electronic Analog Computer provides an excellent means of making parametric studies involving the solution of a number of simultanebus differential equations.

\section{CALCULATION METHODS}

The products of a power reactor are thermal energy and new isotopes, such as plutonium. Some of these isotopes have commercial value which helps to reduce the cost of generating power. Therefore, it is of interest to know how long a reactor must operate on a certain type of fuel to conform to the specifications of a given design. One cost reducing factor calls for maintenance of high reactivity during long irradiation, and the other for removing the fuel after a relatively short time, especially if weapon-grade material is desired. The fuel loading program becomes a problem of determining what combination of fuel characteristics if any can meet the initial specifications and still have enough flexibility to meet anticipated changes in demand for power and plutonium during the lifetime of the reactor.

In the uranium-plutonium system, $U^{235}$ is the primary source of neutrons and plutonium is the secondary. Reactors using this fuel are known as converters, hence the term conversion ratio which is a measure of the efficiency with which fissionable atoms undergo transmutation. Initially, there is no plutonium, but as the $U^{235}$ isotope is depleted it is replaced by the isotopes of plutonium, some of which are fissionable. As the plutonium isotopes build up, their fissions contribute to the fast neutron supply. The $U^{235}$ is replaced by $\mathrm{Pu}^{239}$ and $\mathrm{Pu}^{241}$. At any time there is a continuous evolution taking place (growth and decay) for each of the many isotopes involved. The rate of change in abundarice of each is determined by its own particular nuclear characteristics.

$$
5186 \quad i
$$


The net amount of each at any time is found by a simultaneous integration of -all the equations of isotope transition. From the se net amounts, the variation of reactivity can be determined and expressed in terms of the ratio of multiplication factor at any time $t$ to that at time 0 .

The initial conversion ratio formula consists of two components, that due to thermal absorption and that due to resonance absorption.

\section{Thermal Absorption}

Neutrons absorbed in $U^{238}=\Sigma_{a}^{U}-\Sigma_{a}^{235}$

Resonance Absorption

$$
\begin{array}{ll}
\Sigma_{a}^{235} & =\text { Neutrons absorbed in } U^{235} \\
\Sigma_{a}^{235} \eta \epsilon & =\begin{array}{l}
\text { Number of fast neutrons produced per } \\
\text { thermal neutron absorbed }
\end{array} \\
\sum_{a}^{235} \eta \epsilon(1-p) & =\begin{array}{l}
\text { Number of resonance neutrons captured } \\
\text { per thermal neutron absorbed }
\end{array} \\
\sum_{a}^{235}(p) e^{-B^{2} T} & =\begin{array}{l}
\text { Number of fast neutrons remaining after } \\
\text { leakage }
\end{array}
\end{array}
$$

Total Initial Conversion Ratio

$$
I C R=\frac{\Sigma_{a}^{238}}{\sum_{a}^{235}}+\eta \epsilon(1-p) e^{-B^{2} \tau}
$$

The symbols used throughout have their conventional meaning.

As irradiation proceeds, the conversion ratio is defined by the following expressions:

The instantaneous conversion ratio at any time is defined as the ratio of the rate of production of new fissionable isotopes to the rate of destruction of old fissionable isotopes.

The cumulative conversion ratio at any time is defined as the ratio of the number of fissionable atoms existing at that time to the number of fissionable atoms existing at the beginning of the irradiation. 
The primary chain of reactions is considered to give satisfactory results. The chain extends from $\mathrm{U}^{238}$ to $\mathrm{Pu}^{241}$. This chain of reactions is shown on Figure I. The equations which give the rate of change of each isotope are shown on Figure II. The rate of change of each can be determined, and the integration of all isotopic changes simultaneously gives the net amount present at any time $t$.

Only thermal fission is considered in determining the rate of change. While it is recognized that there are many branching reactions with yields for fission and neutron capture products, they are not considered individually but are lumped and given a cross section of 50 barns per fission product pair. It is recognized that the fission product cross section varies with irradiation time, but there are so many unknowns involved that this cross section is left constant at 50 barns until a more erudite explanation of the phenomena is available.

The variation of $\mathrm{U}^{238}$ due to thermal and resonance absorption is taken into account. The effect of resonance capture in plutonium is not taken into account because not enough is known about it at the present. It is felt that it may be equivalent to increasing the cross section of $\mathrm{Pu}^{239}$ by $10 \%$ or more. The effect of a $10 \%$ increase in $\mathrm{Pu}^{239}$ cross section is shown in Figure III.

The power is held constant; therefore, the flux is a function of time and is so treated in the solution of the equations listed in Figure II.

All calculations are made for a point in the reactor at which the fuel and moderator are considered homogeneous and neutron temperature equal to moderator temperature at $293^{\circ} \mathrm{K}$.

Allowances are made for fast fission, leakage, and resonance absorption of fast neutrons in the examples of "typical reactors" presented.

The reactivity is expressed in terms of the multiplication factor $k_{\infty}$.

$$
\mathbf{k}_{\infty}=\epsilon \mathbf{p} \eta \mathbf{f}
$$

It is assumed that $\epsilon$ and $\mathrm{p}$ do not change since the amount of $\mathrm{U}^{238}$ and the value of the microscopic cross sections do not vary appreciably over the range of irradiations studied. Therefore, $k$ can be considered to vary as $\eta f$ and reactivity to vary as $\eta f / \eta_{0} f_{0} . k_{\infty}$ is used because it is independent of the just critical multiplication constant $\mathrm{k}_{\infty}(0)$. 
There is little latitude in the evaluation of " $\eta$ " since it is fixed by the characteristics of the fuel, but " $f$ " is flexible because $\Sigma$ Xe + Sm + Mod + Structure and $\Sigma_{a}^{\text {fission products }}$ constitute a large percentage of the denominator in the expression for $f$.

\section{RESULTS}

The theoretical studies have been concerned with irradiations up to $20,000 \mathrm{mwd} /$ ton at fluxes of the order of $10^{13}$.

The calculations cover the following combinations of enrichments and - conversion ratios.

$\%$ Enrichment

0.50

. 0.60

0.72

0.80

0.90

1.00

1.25

1.50

1.75

2.00

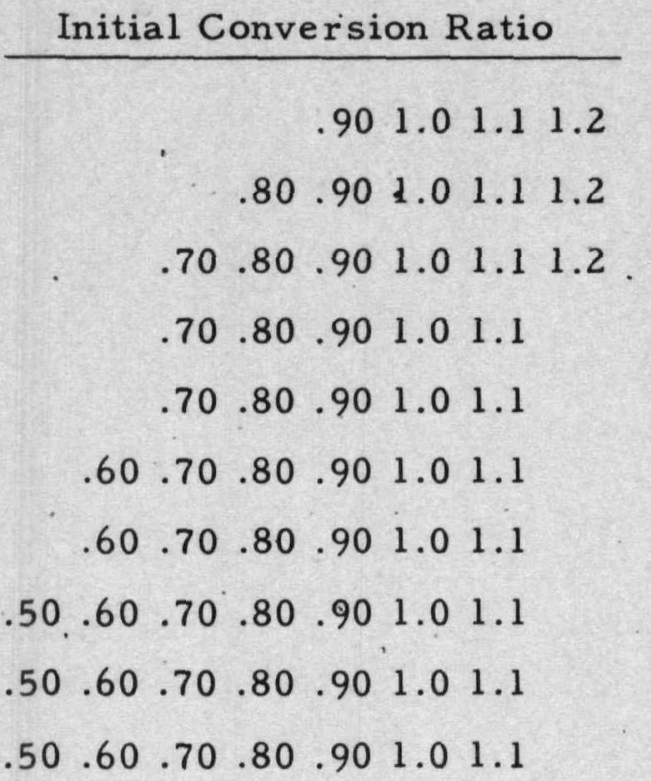

Figures IVa to IVj contain the isotopic abundance curves of $\mathrm{U}^{238}$, $\mathrm{U}^{235}, \mathrm{Pu}^{239}, \mathrm{Pu}^{240}$, and $\mathrm{Pu}^{241}$. This presentation of the solution of the equations in parametric form covers the area of current interest. Interpolation between the plotted values gives satisfactory results.

The values of " $\eta$ " and " $f$ " can be calculated by using the net amounts of each isotope at time $t$, and the variation in reactivity expressed in terms of the ratio of $\left(\eta f / \eta_{0} f_{0}\right)$ plotted against irradiation time, which can be either expressed in per cent burnup of $\mathrm{U}^{235}, \mathrm{mwd} / \mathrm{ton},(\phi \mathrm{t})$ or time.

It has been found convenient to use the integrated energy release (mwd/ton) as the abscissa in all those figures which show reactivity variations as a function of irradiation time. The variation in reactivity, as indicated by the ratio $\eta \mathrm{f} / \eta_{0} \mathrm{f}_{0}$, has been determined for a thermal reactor using natural 
uranium and for several specific designs discussed in this report. Other values of $\eta f / \eta_{0} f_{0}$ as a function of irradiation time can be found by calculating " $\eta$ " and " $f$," using the values of isotopic abundance curves found in Figure IVa to IVj. These curves were constructed on the basis of a constant specific power $=19.27 \mathrm{mw} /$ ton. In case the flux is other than that shown in combination with a given enrichment, vary the irradiation time scale directly as the flux ratio. For example, to determine from Figure IVa the isotopic abundance in a reactor which has been operating for $4 \times 10^{7} \mathrm{sec}$ and had an initial thermal flux and initial enrichment of $3.3 \times 10^{13}$ and $0.5 \%$, respectively, enter the time scale with $1.4 \times 10^{7} \mathrm{sec}$. This is not strictly correct because the variation with time of two different initial fluxes is not necessarily in phase. However, for small variations in flux the discrepancy is considered negligible.

In case the enrichment is other than and lies between the values considered on IVa to IVj, it is necessary to interpolate because the curves of isotopic abundance are calculated on the basis of a definite relationship between the number of atoms of $U^{235}$ and $U^{238}$ at any time diring the irradiation.

Figure $\mathrm{V}$ is a graphical representation of reactivity vs. irradiation time with initial conversion ratio as parameter for a thermal reactor using natural uranium as fuel.

Consider the curve of reactivity designated $(I C R=1.0)$. If the initial loading is left intact and the power is held constant, it is apparent that the reactivity increases at first due to the favorable relationship between fissionable and absorbing material and then decreases steadily with time.

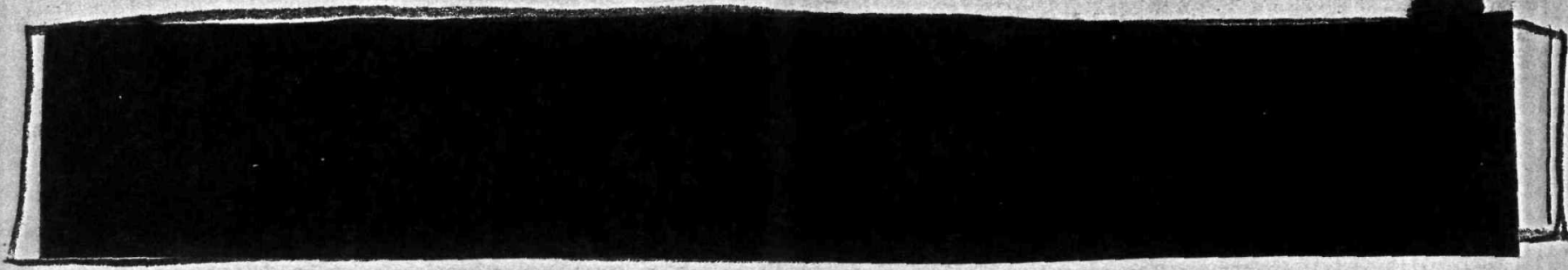

If it is feasible to arrange the loading program so that there are many incremental changes in fuel during a predetermined operating period (so that the variation in reactivity is the cumulative average at any time), it is possible to operate for much longer periods with the same loss in reactivity as would occur in the case where the fuel was left intact during the entire irradiation period. This corresponds to a case where the average exposure of all fuel in the reactor is one-half the maximum exposure at discharge.

The average loss (as defined above) in reactivity vs. irradiation time is shown on Figure VI. For the same loss of reactivity $(4.3 \%$ for ICR = 1$)$ the operating time is now $16,000 \mathrm{mwd} /$ ton instead of 7,000 . It is apparent that a substantial increase in irradiation time can be achieved by incremental loading over a period of operation. In this case, 1/16 of the fuel would be changed every $1000 \mathrm{mwd} / \mathrm{ton}$. 
Recently, experimental work has been performed at Argonne to determine the conversion ratio of uranium $\mathrm{D}_{2} \mathrm{O}$ lattices. A curve of $\mathrm{k}-1 \mathrm{vs}$. conversion ratio was made from the data of this experiment and superimposed on a plot of $(\mathrm{k}-\mathrm{l}) \mathrm{vs}$. initial conversion ratio with $\mathrm{mwd} / \mathrm{ton}$ as parameter, constructed from the natural uranium reactivity curves, Figure VI. The intersection points of the two sets of curves (Figure VII) relates excess reactivity, conversion ratio, power, and operating time.

Figure VIII shows the effect of enrichment upon variation in " $\eta$." The specific power and initial conversion ratio are held constant for enrichments of $0.5 \%, 0.72 \%$, and $2.0 \%$. In addition, the effect of a combined increase in enrichment and lowering of conversion ratio is shown. It is noted that the curves for equal conversion ratio tend to converge at about $11,500 \mathrm{mwd} / \mathrm{ton}$, and then diverge. It is planned to investigate this phenomenon.

Reactivity variations in three typical reactors are shown on Figure IXa. These specific designs are the boiling $\mathrm{D}_{2} \mathrm{O}$ reactor, the light water reactor, and the sodium-graphite reactor.

\begin{tabular}{|c|c|c|c|}
\hline & $\begin{array}{c}\text { Sodium } \\
\text { Graphite* } \\
\end{array}$ & Light Water. & $\begin{array}{c}\mathrm{D}_{2} \mathrm{O} \\
\text { Boiling } \\
\end{array}$ \\
\hline Enrichment - \% & 1.25 & 1.15 & 0.72 \\
\hline ICR & 0.85 & 0.95 & 1.00 \\
\hline$\epsilon$ & 1.03 & 1.06 & 1.04 \\
\hline $\mathrm{p}$ & 0.77 & 0.701 & 0.82 \\
\hline f & 0.86 & 0.95 & 0.935 \\
\hline
\end{tabular}

*Illustrative examples, not necessarily the optimum.

The nuclear constants are the same as those listed in Appendix I. The $\Sigma_{a}^{X e}+\mathrm{Sm}+\mathrm{Mod}+$ Structure is assumed to be $5 \%$ of the initial $\Sigma_{a}^{\text {fuel }}$ and is held constant throughout the irradiation period.

The cross section for fission fragments was taken at 50 barns per fission product pair.

The deviation between the three types of reactors is not as much as one might expect from the foregoing discussion. A breakdown of the product $(\eta f)$ and plot of each vs. irradiation time, Figures IXb and IXc, show why. this is so. In the high enrichment reactors the $\Sigma_{a}^{X e}+\mathrm{Sm}+\mathrm{Mod}+$ Structure constitutes a larger constant in the denominator of the expression for "f."

$$
f=\frac{\sum_{a}^{\text {fuel }}}{\Sigma \text { fuel }+\sum \text { fission products }+\sum \text { Xe }+ \text { Sm }+ \text { Mod }+ \text { Structure }}
$$


The average value of $\left(\frac{\eta f}{\eta_{0} f_{0}}\right)$ due to incremental loading for these three reactors is shown in Figure IXd.

The effect of enrichment upon the production of weapon-grade plutonium is shown in Figure $\mathrm{X}$. It is apparent that the ratio of $\mathrm{Pu}^{240}$ to $\mathrm{Pu}^{239}$ varies approximately inversely as the enrichment for constant power.

\section{METHODS OF MAINTAINING REACTIVITY}

There are a number of ways in which a characteriștic reactivity curve can be artificially altered so as to prevent to some degree the loss of reactivity with time. All of them have some concomitant disadvantages which must be weighed against the advantages.

1. The length of time between major changes of fuel can be extended indefinitely if fissionable material is added during operation. It would require an economic study of the specific problem to determine whether this method of maintaining reactivity is too costly. Note, too, that as additional fissionable material is added, the conversion ratio decreases and the rate of reactivity loss becomes more rapid. The practical interpretation of this is that the amount of $\mathrm{U}^{235}$ which must be added is greater than the amount calculated from the deficit in reactivity indicated on the curves in this report.

2. The use of $P^{240}$ control rods has some theoretical advantages. In time, the $\mathrm{Pu}^{240}$ would change from an absorber to a source of fissionable $\mathrm{Pu}^{241}$ atoms. The greatest difficulty at present is due to the fact that there is no source of supply for $\mathrm{Pu}^{240}$. From the shapes of the reactivity versus time curves, it appears that the equilibrium mixture of $\mathrm{Pu}^{239}, \mathrm{Pu}^{240}$, and $\mathrm{Pu}^{241}$ might maintain reactivity essentially constant over a long period of time.

3. Thorium could be loaded into the reactor along with the initial uranium loading. The characteristic reactivity curve of thorium is opposite to that of U-Pu system, and they would tend to counteract each other, thus maintaining a constant reactivity with time.

4. Another method which can be used in reactors which have a ratio of fuel to moderator greater than optimum and good neutron economy is to remove fuel whenever the reactivity decreases to a certain level. This in turn increases $p$ and reduces the ICR. The reactivity increases about $1 \%$ for every $1.7 \%$ decrease in conversion ratio. This procedure is illustrated in Figure XI. The obvious disadvantage of this method is the loss in power every time fuel is removed.

obvious.

There are doubtless many other methods, but these seem most 


\section{ACKNOWLEDGEMENT}

Acknowledgement is made for assistance, suggestions, and criticisms from the following:

H. K. Clark

H. Greenspan

L. C. Merrill

D. Metta

G. I. Moller

N. F. Morehouse

S. Untermyer 


\section{APPENDIX I}

\section{Cross Section and Nuclear Constants}

The following values were used throughout:

$\begin{array}{cccccccc} & \mathrm{U}^{235} & \mathrm{U}^{238} & \mathrm{U}^{239} & \mathrm{~Np}^{239} & \mathrm{Pu}^{239} & \mathrm{Pu}^{240} & \mathrm{Pu}^{241} \\ \sigma_{\mathrm{a}} \times 10^{24} & 640 & 2.8 & & & 1150 & 540 & 1420 \\ \sigma_{\mathrm{f}} \times 10^{24} & 540 & 0 & & 765 & 0 & 1060 \\ \sigma_{\mathrm{c}} \times 10^{24} & 100 & 2.8 & & 385 & 540 & 360 \\ \eta & 2.12 & & 2.02 & & 2.2 \\ \nu & 2.51 & & & 2.95 & & 2.95 \\ \lambda & & & 23.5 \mathrm{~m} & 2.3 \mathrm{~d} & & & \end{array}$

A change in the value of any nuclear constant would, of course, alter the shape of the curves shown on Figure IV a - j and, in turn, the shape of the reactivity curve. The method of solution is so flexible that any changes in the value of the constants can be readily integrated into the solution. 
Figure I

\section{URANIUM - PLUTONIUM REACTION}

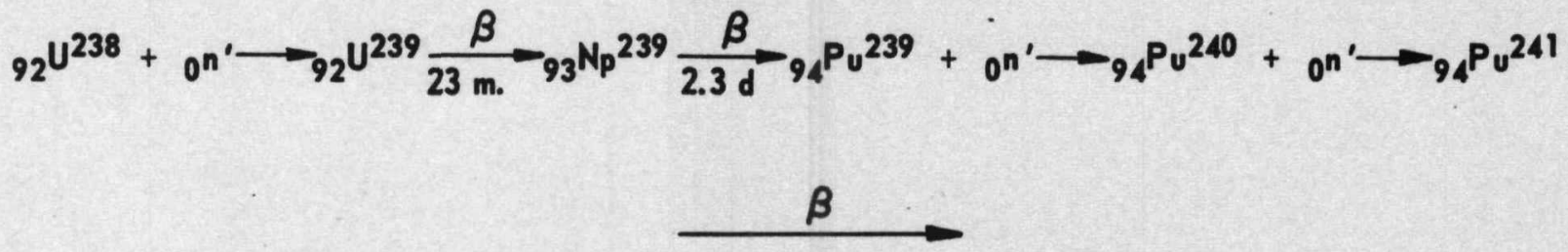

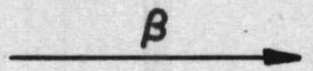

1
$\bar{x}$
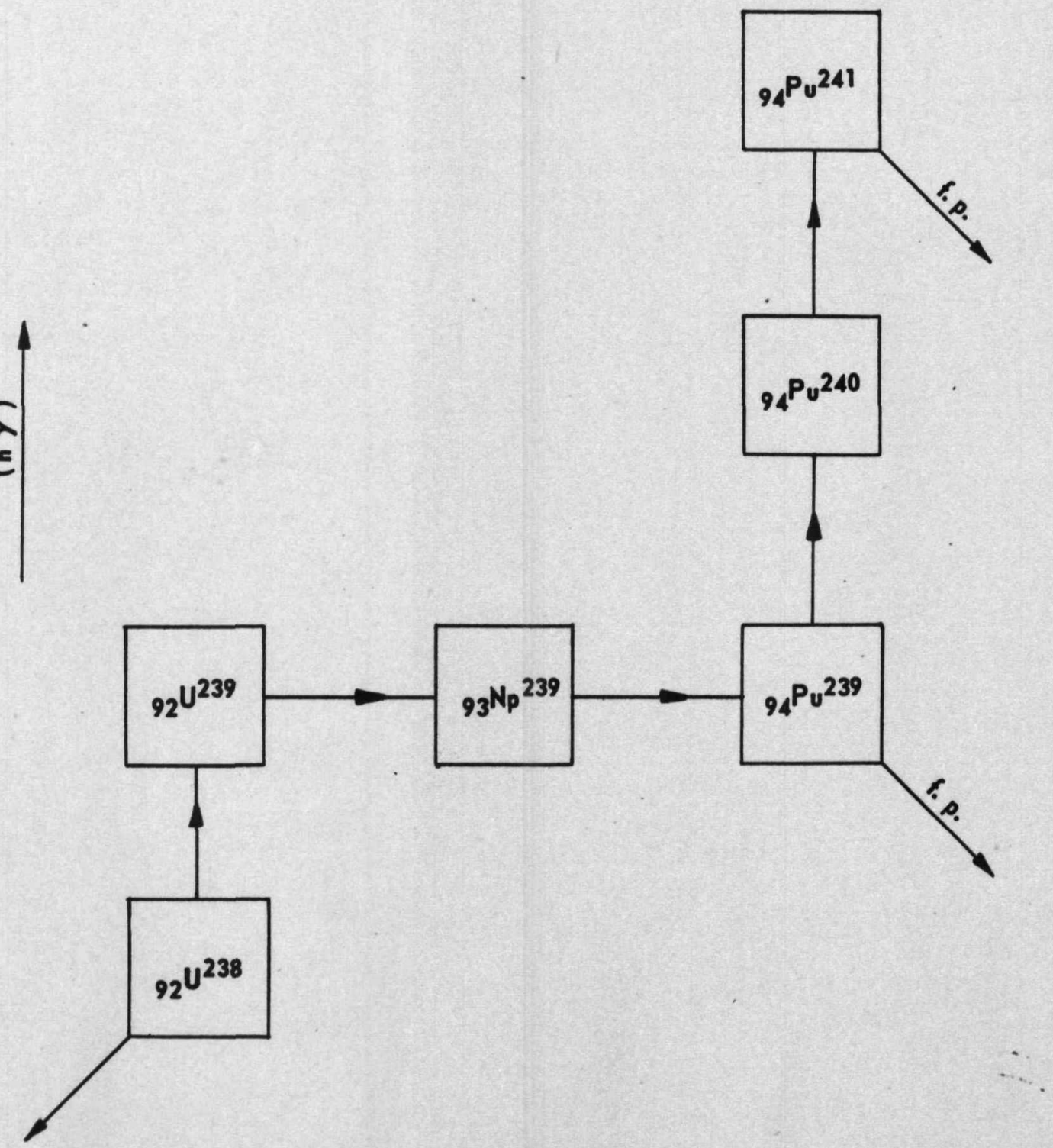

$5186 \quad 16$ 
Figure II

\section{URANIUM-PLUTONIUM REACTION}

\section{EQUATIONS OF ISOTOPIC ABUNDANCE}

$$
\begin{aligned}
& U^{235} \quad \frac{d U^{235}}{d t}=-\phi_{(t)} \sigma_{a} U^{235} \\
& U^{238} \frac{d U^{238}}{d t}=-\phi_{(t)}\left\{\sigma_{a} U^{238}+\epsilon(1-p) e^{-\beta 2 \tau}\left(\sigma_{a} U^{235} \eta+\sigma_{a} P_{u}^{239} \eta+\sigma_{a} P_{u} 241 \eta\right)\right\} \\
& U^{239} \frac{d U^{239}}{d t}=\phi_{(t)}\left\{\sigma_{a} U^{238}+\epsilon(1-p) e^{-\beta^{2} \tau}\left(\sigma_{a} U^{235} \eta+\sigma_{a} P_{u}^{239} \eta+\sigma_{a} P_{u}^{241} \eta\right)-\lambda U^{239}\right\} \\
& N_{p} 239 \frac{d N_{p} 239}{d t}=\lambda U^{239}-\lambda N_{p} 239 \\
& P_{u} 239 \frac{d P_{u}^{239}}{d t}=\lambda N_{p}^{239}-\phi_{(t)} \sigma_{a} P_{u} 239 \\
& P u^{240} \frac{d P u^{240}}{d t}=\phi_{(t)}\left\{\sigma_{c} P u^{239}-\sigma_{a} P u^{240}\right\} \\
& P_{v} 241 \frac{d P_{u}^{241}}{d t}=\phi_{(t)}\left\{\sigma_{a} P_{u}^{240}-\sigma_{a} P_{u} 241\right\} \\
& \phi_{(t)}=\frac{K}{\sigma f U^{235}+\sigma f P^{239}+\sigma f P^{241}} \\
& \text { Power }=\frac{\phi_{(t)} \sigma f V N}{3.1 \times 10^{10}} \text { (Watts) }
\end{aligned}
$$




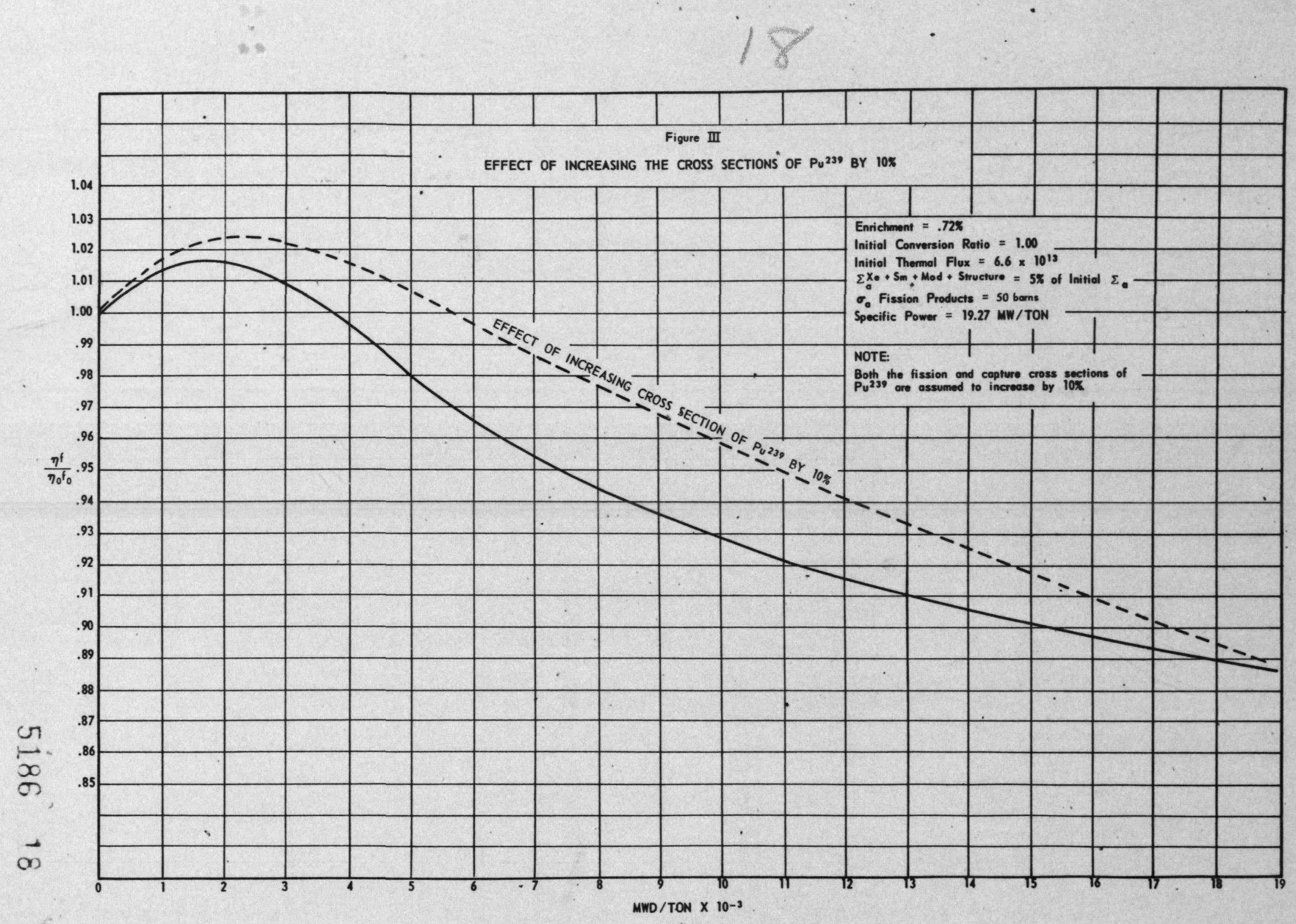


Fig. IV

$a-j$

\% Enrichment

Initial Conversion Ratio

a

.50

b

c

d

e

f

g

$\mathrm{h}$

i

j
.60

.72

.80

.90

1.00

1.25

1.50

1.75

2.00 $\begin{array}{llll}.90 & 1.0 & 1.1 & 1.2\end{array}$

$\begin{array}{llllll}.80 & .90 & 1.0 & 1.1 & 1.2\end{array}$

$\begin{array}{llllll}.70 & .80 & .90 & 1.0 & 1.1 & 1.2\end{array}$

$\begin{array}{lllll}.70 & .80 & .90 & 1.0 & 1.1\end{array}$

$\begin{array}{lllll}.70 & .80 & .90 & 1.0 & 1.1\end{array}$

$\begin{array}{lllllll}.60 & .70 & .80 & \ddots 90 & 1.0 & 1.1\end{array}$

$\begin{array}{llllll}.60 & .70 & .80 & .90 & 1.0 & 1.1\end{array}$

$\begin{array}{llllll}.50 & .60 & .70 & .80 & .90 & 1.0\end{array}$

$\begin{array}{llllll}.50 & .60 & .70 & .80 & .90 & 1.0\end{array}$

$\begin{array}{llllll}.50 & .60 & .70 & .80 & .90 & 1.0\end{array}$ 


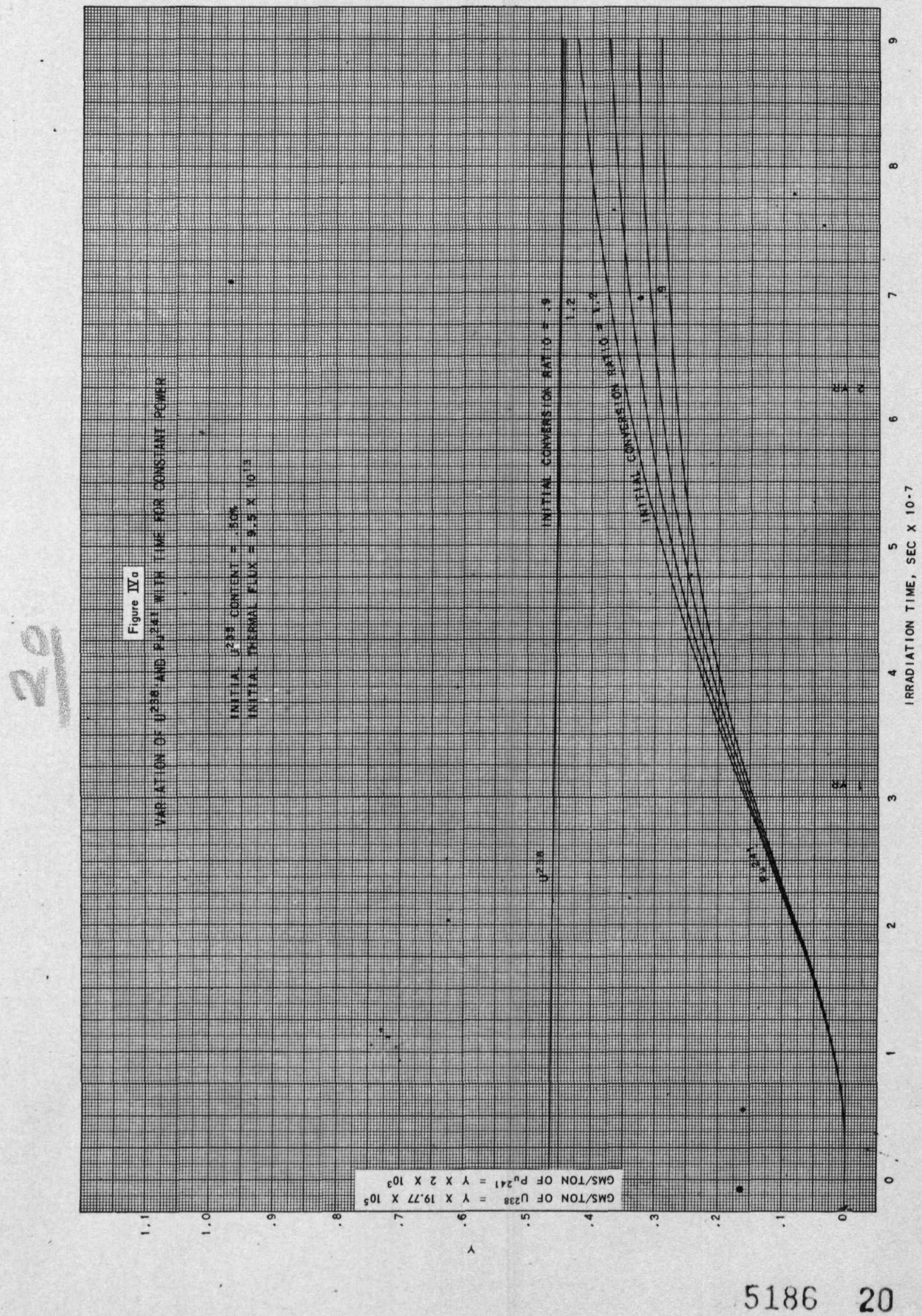




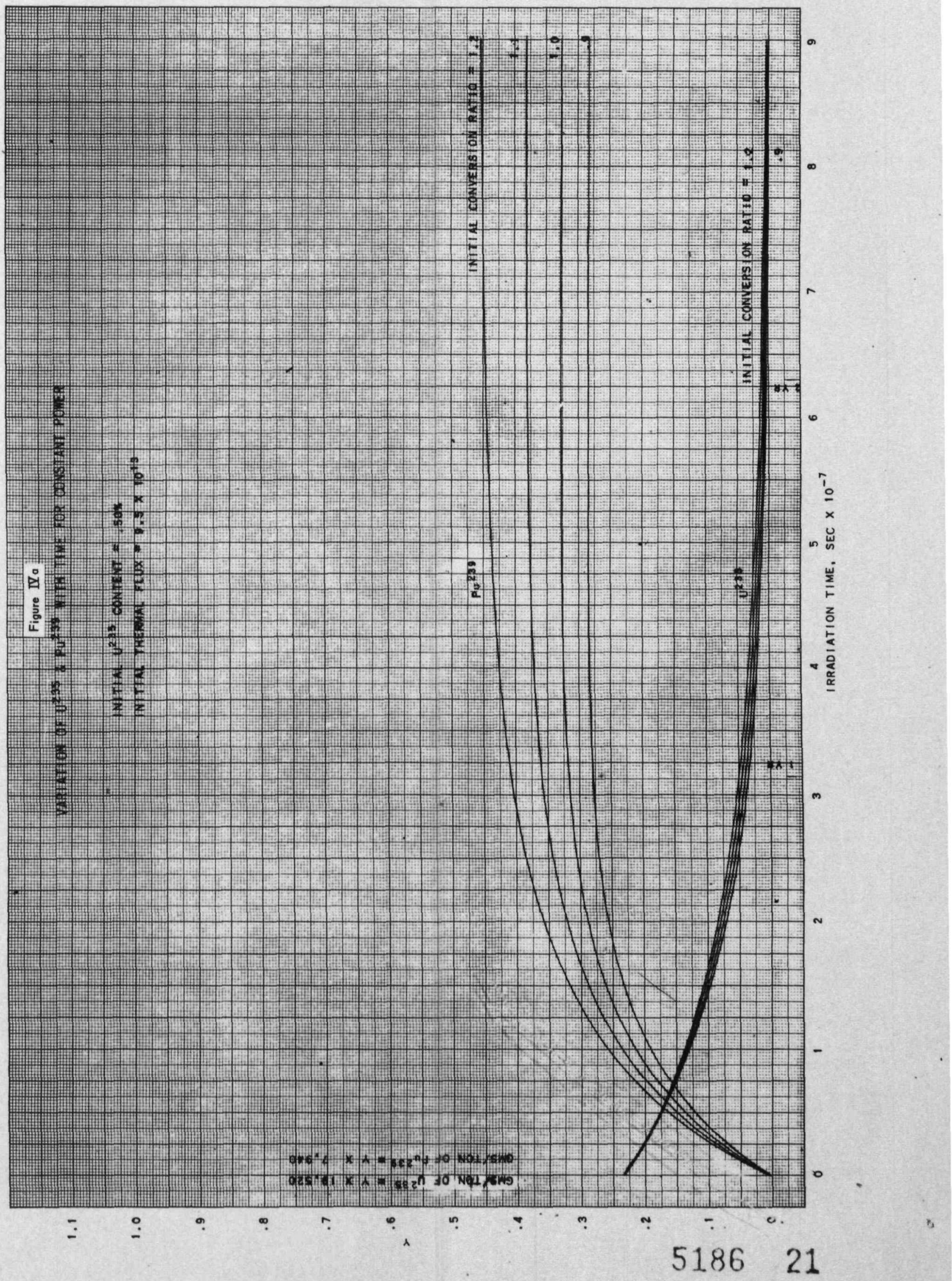




\subsection{9}

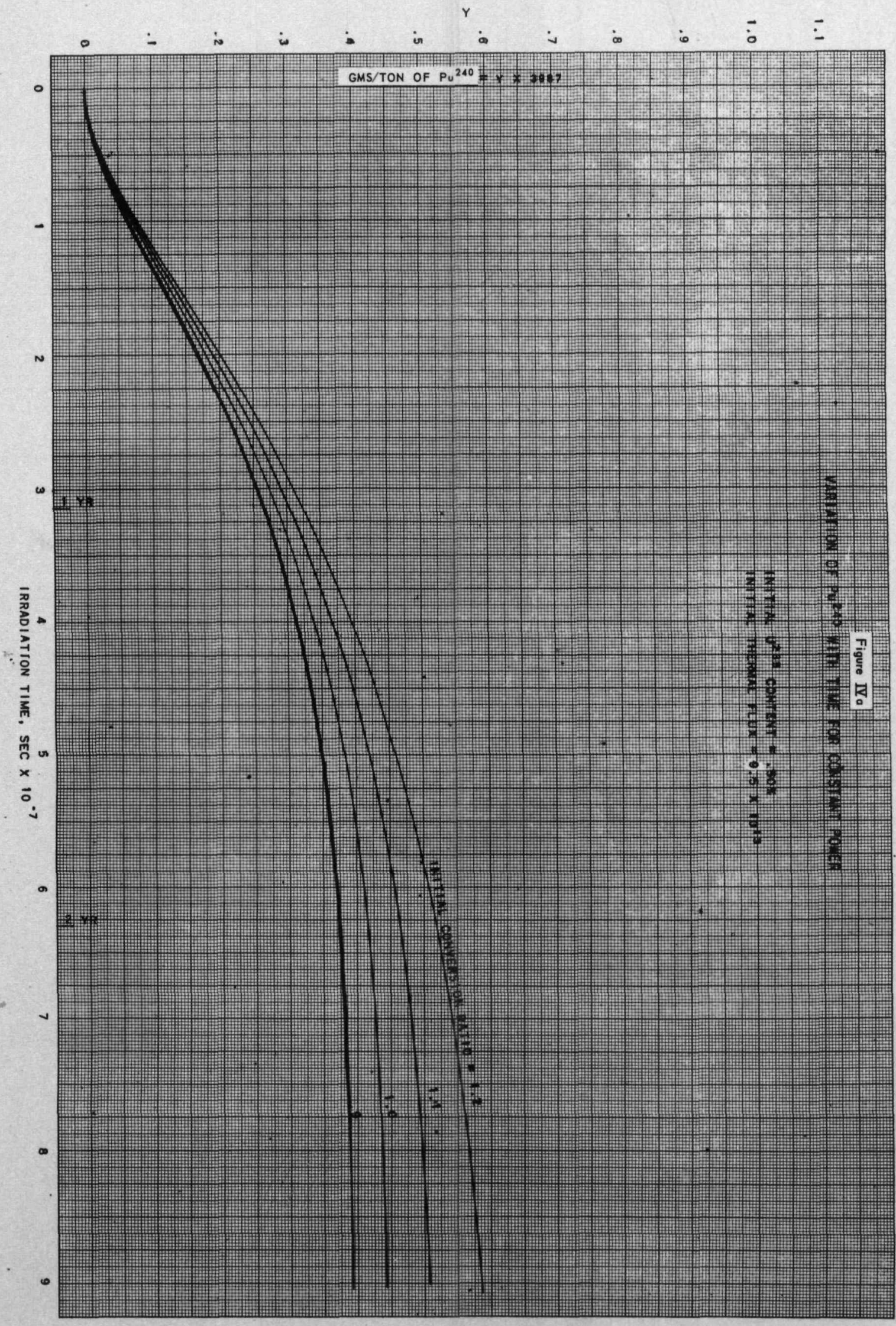




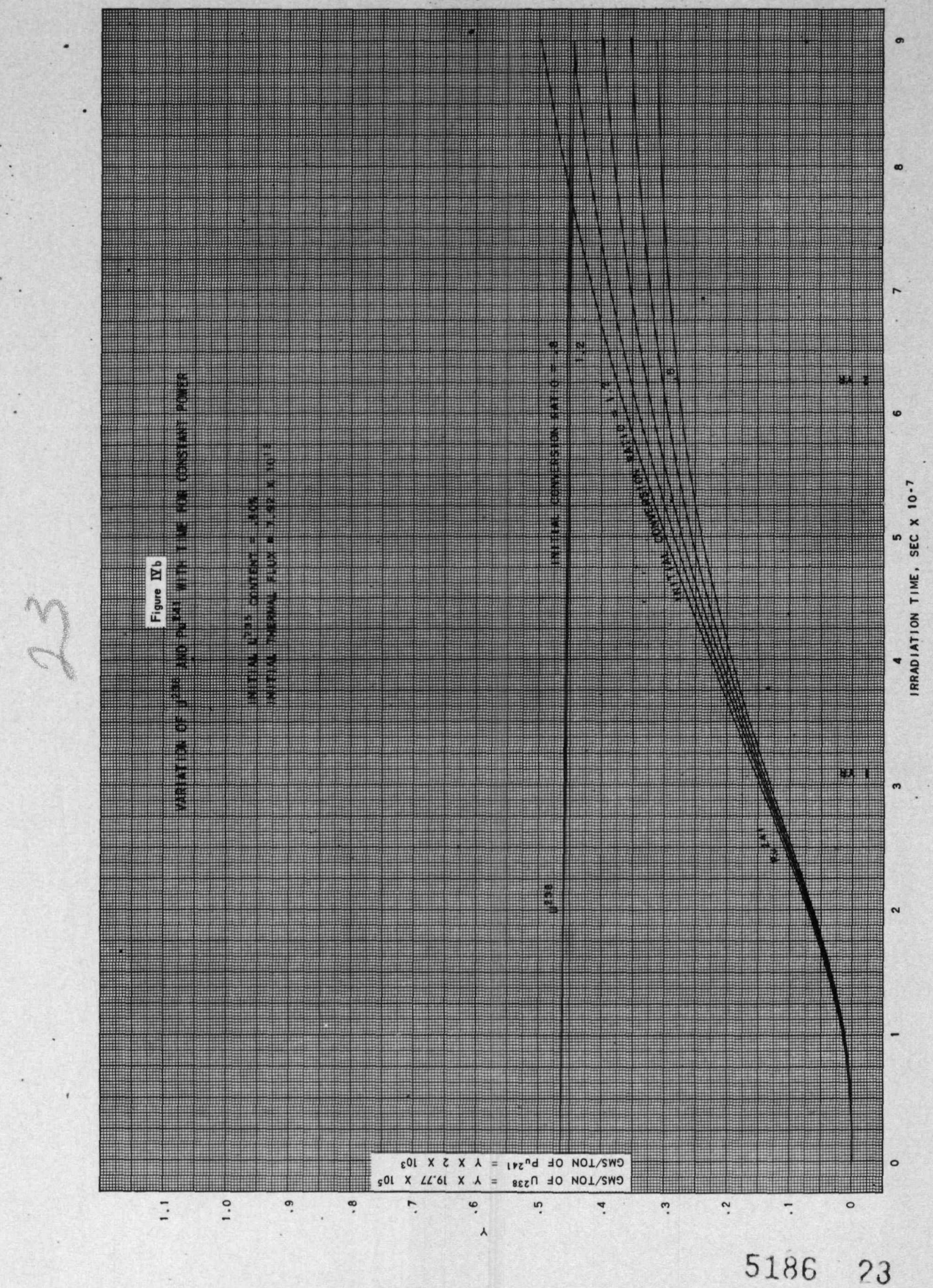




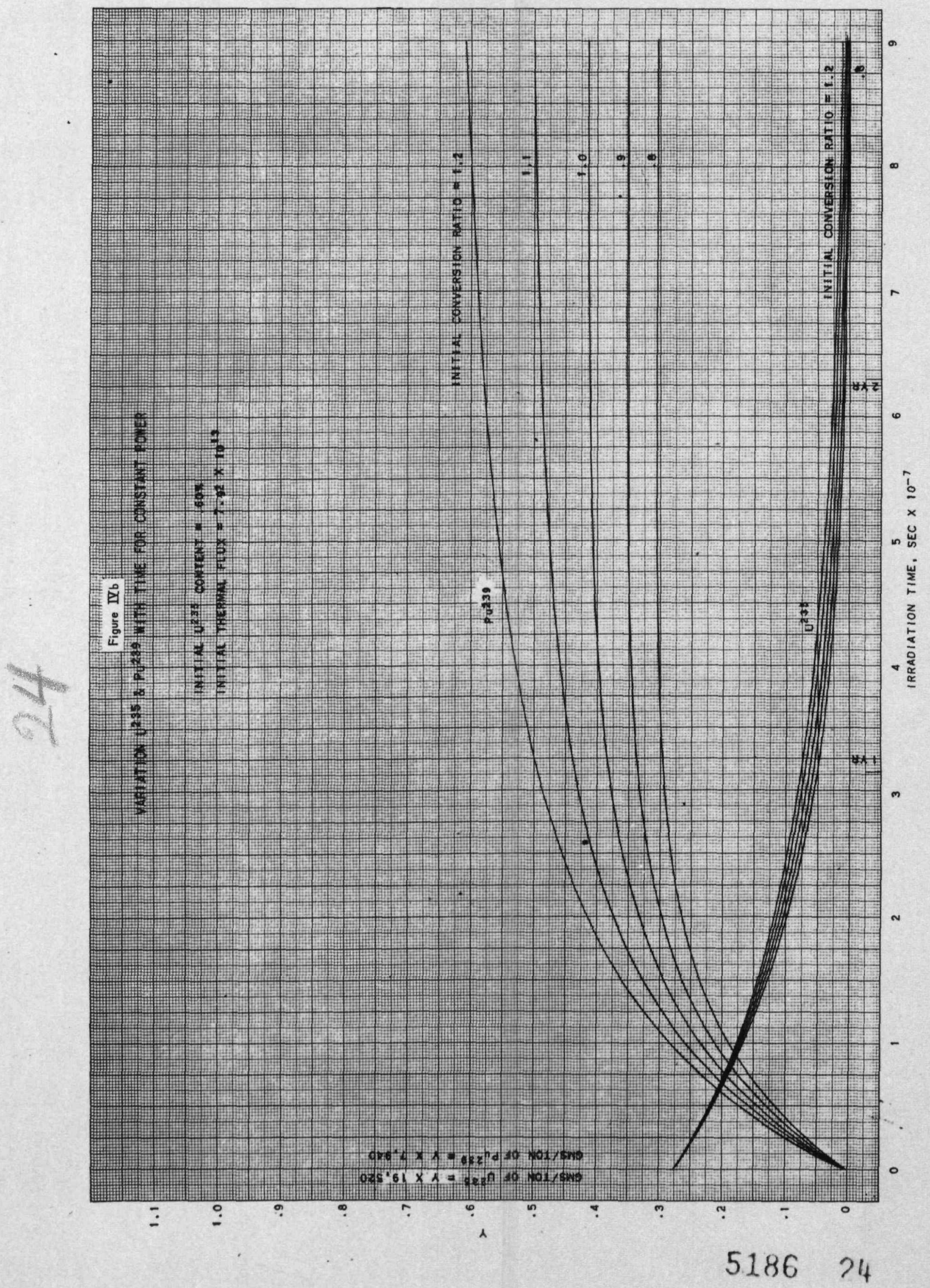




\section{SL 98IS}

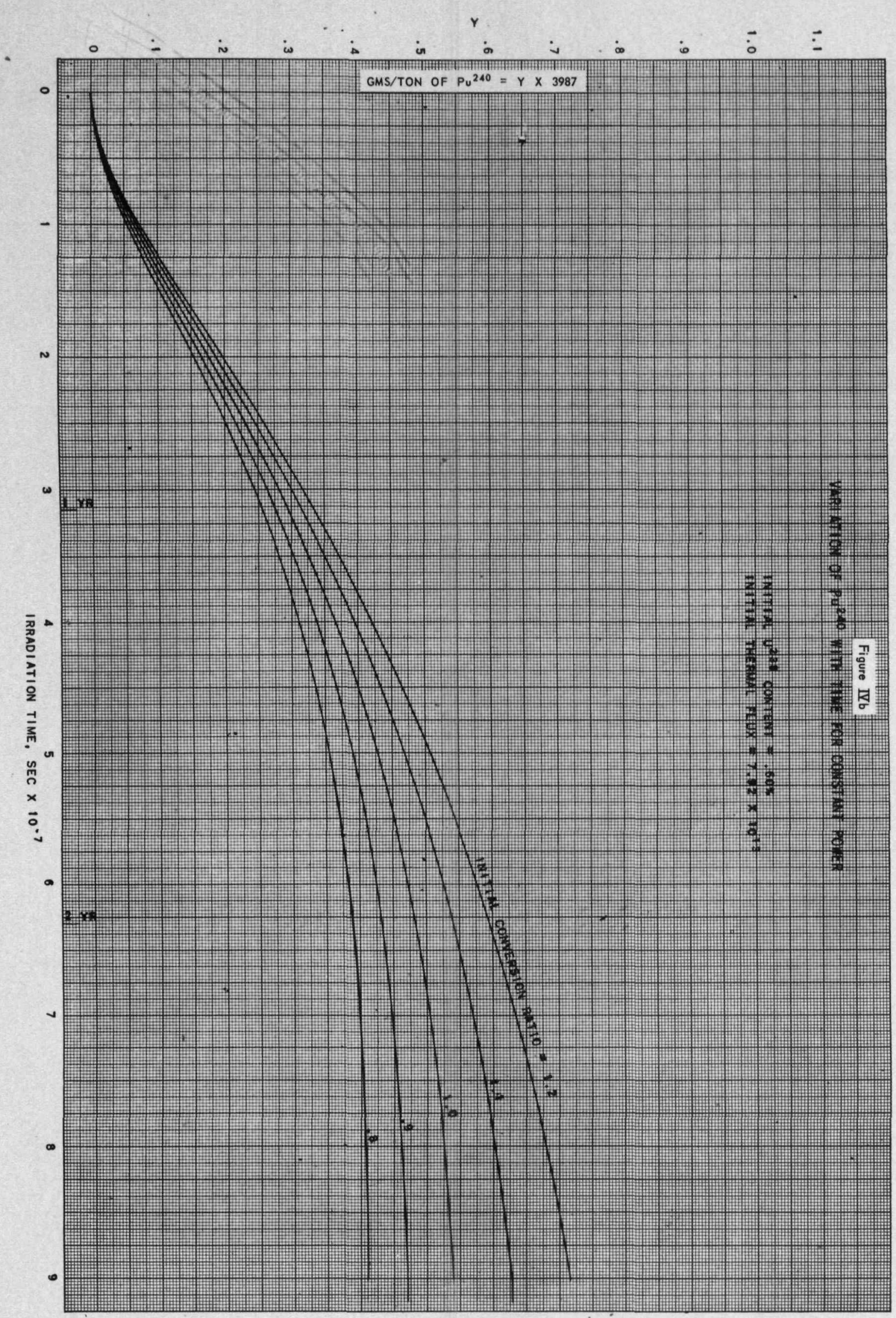




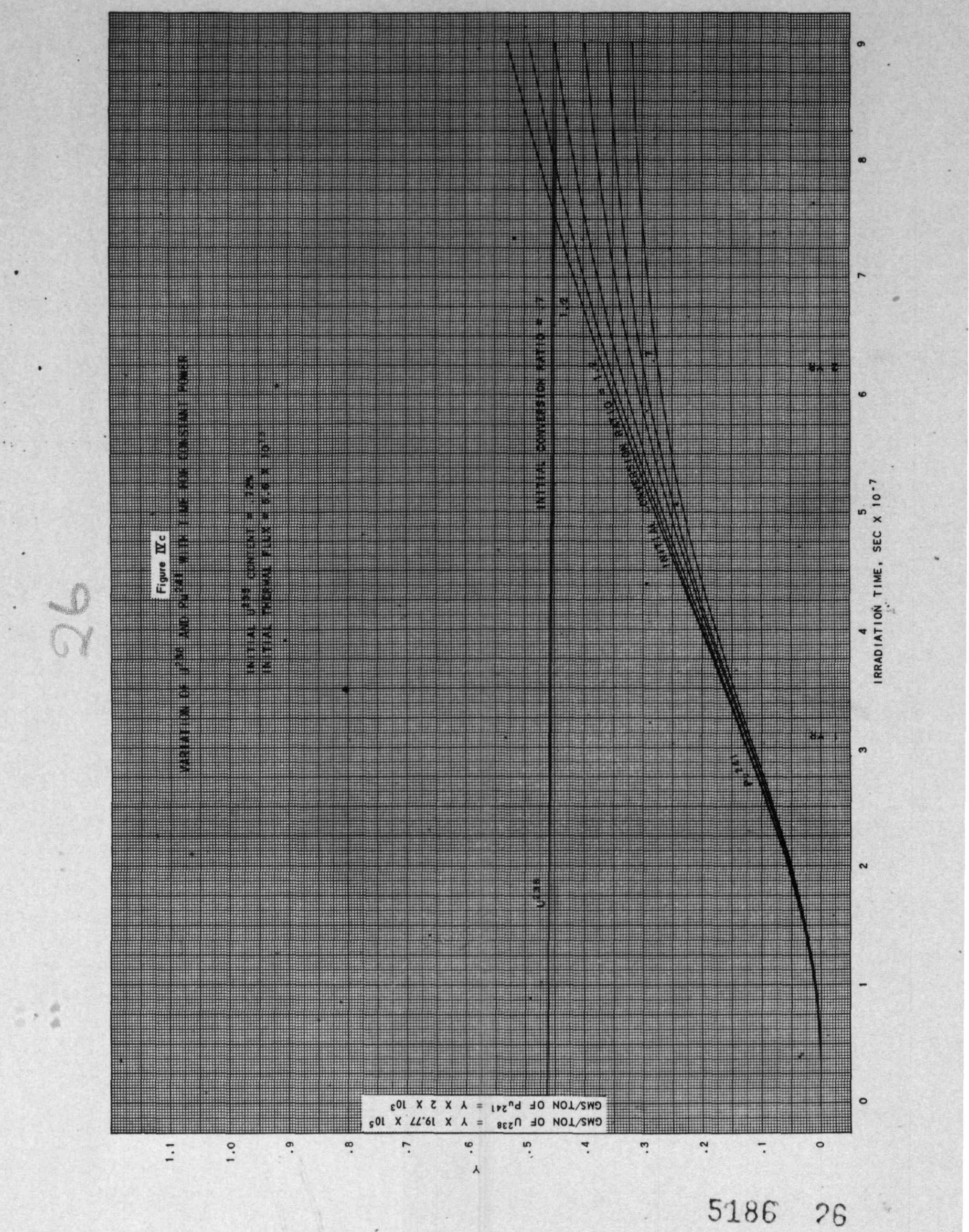




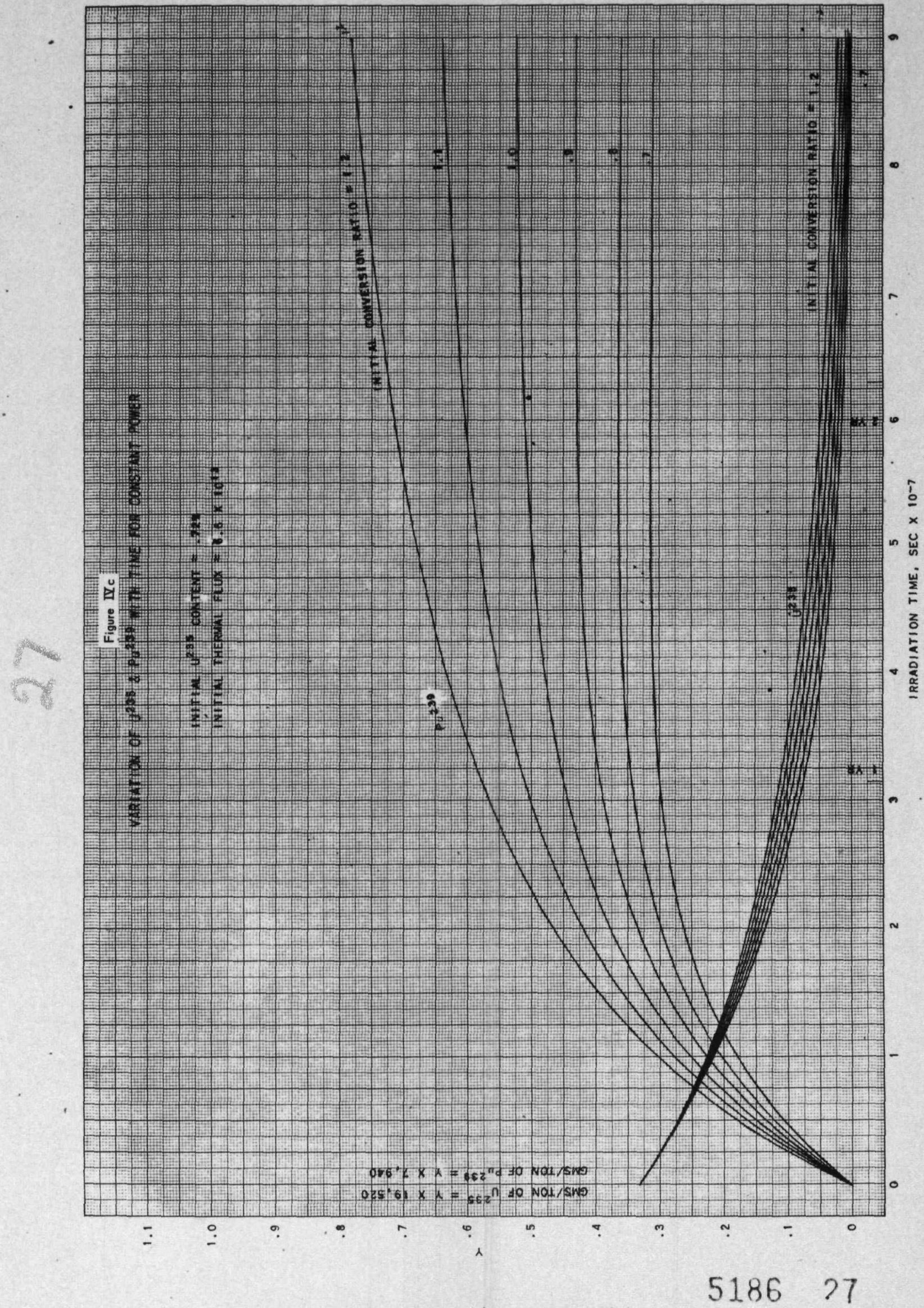




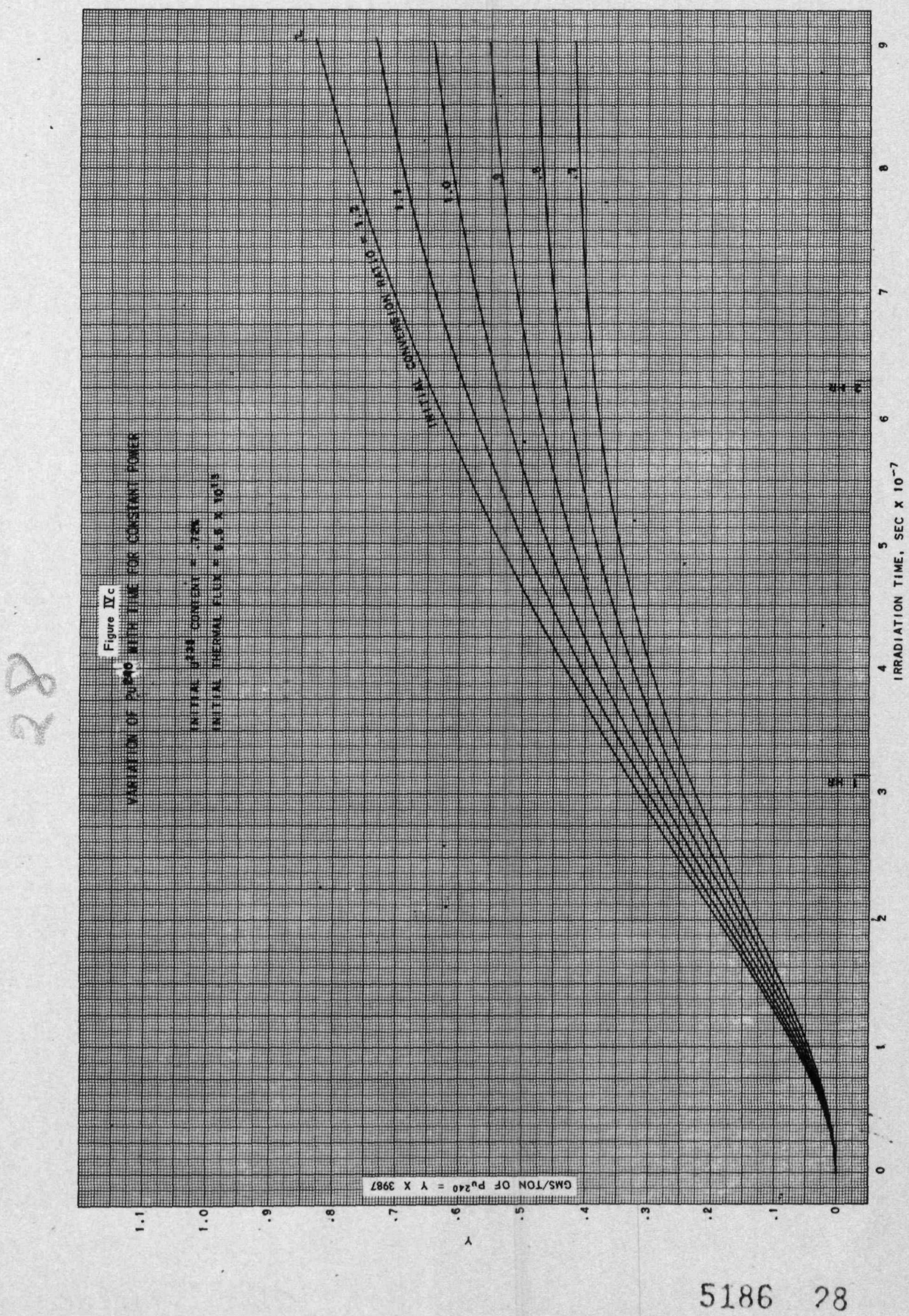




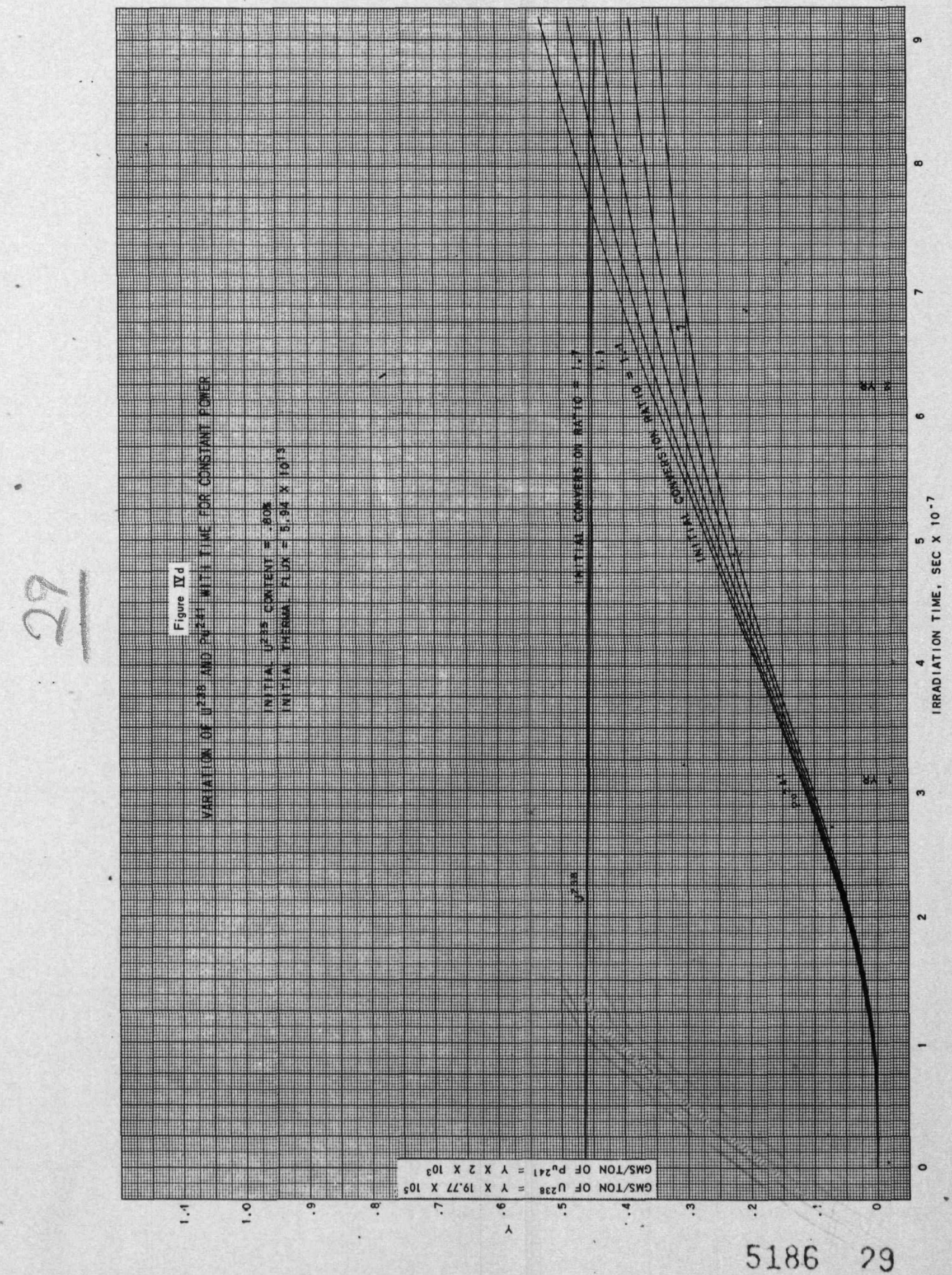




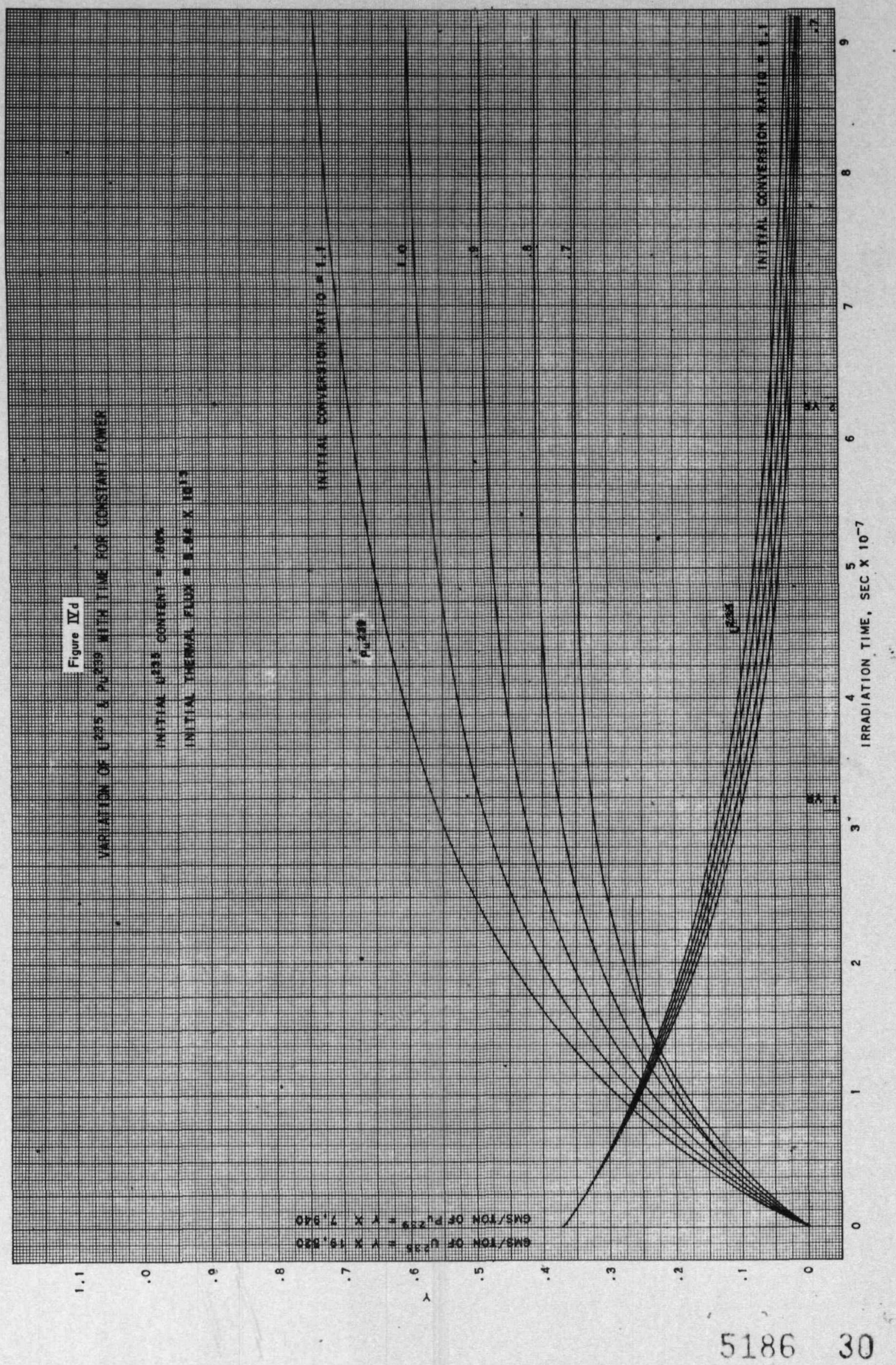




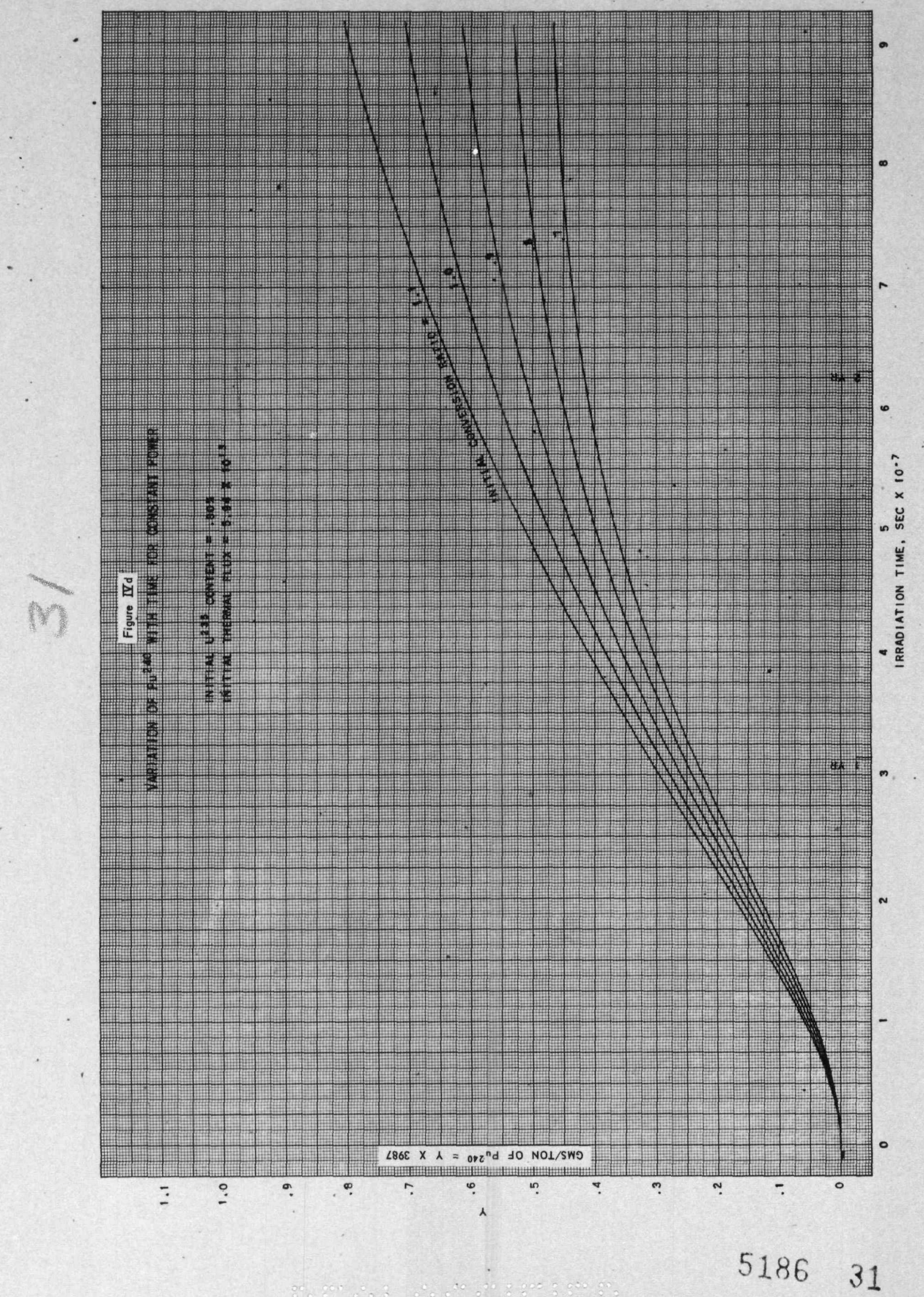




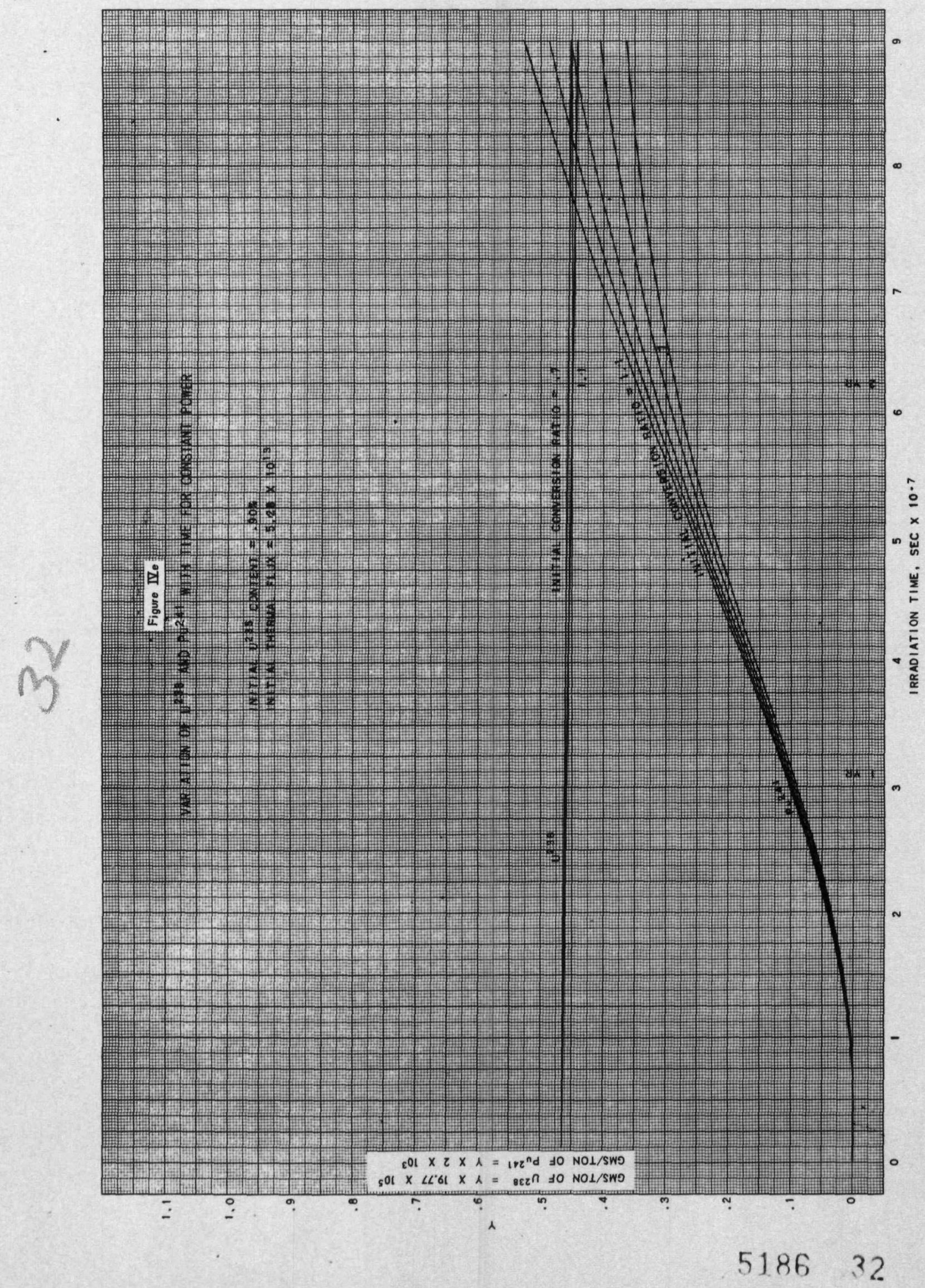




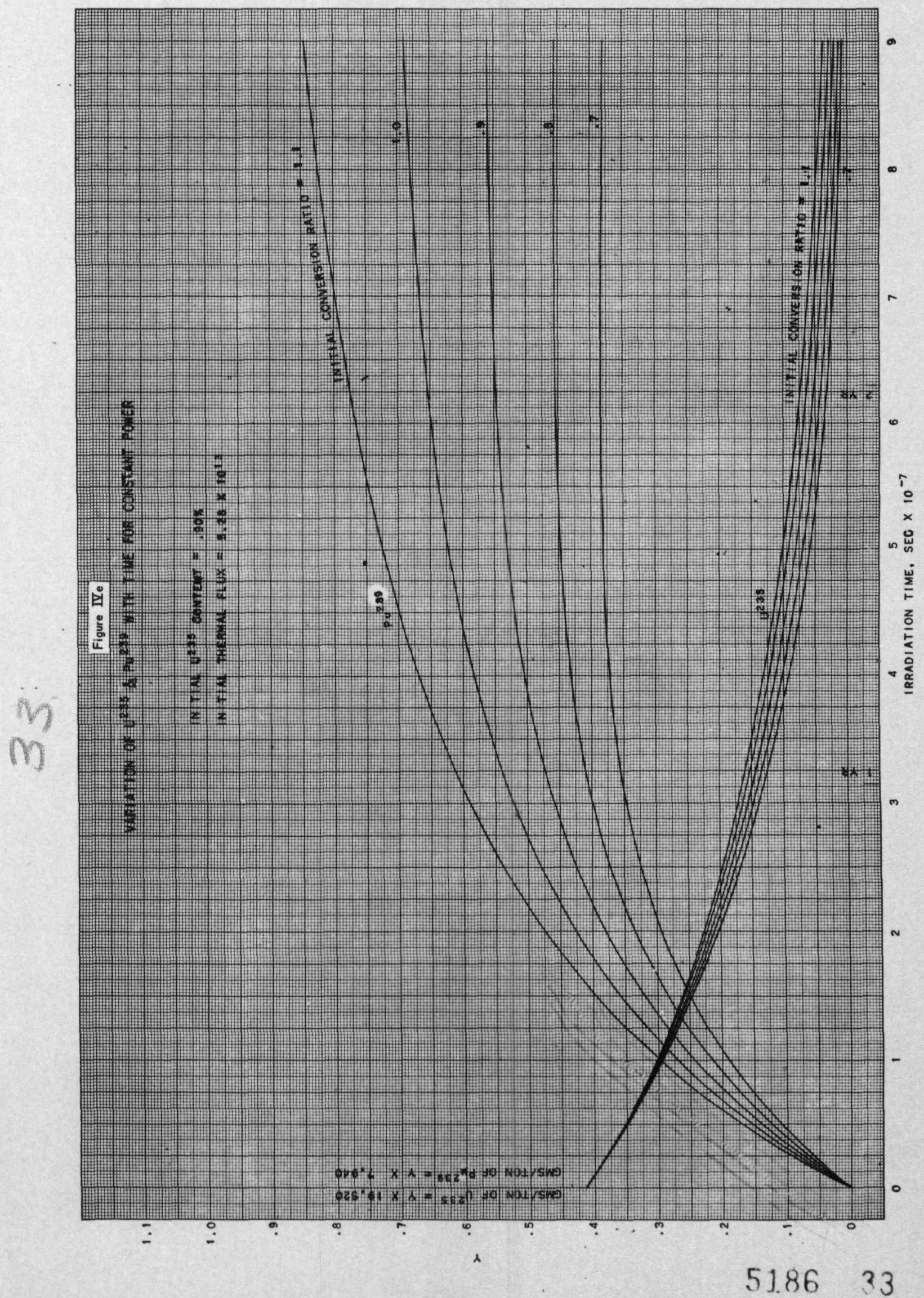




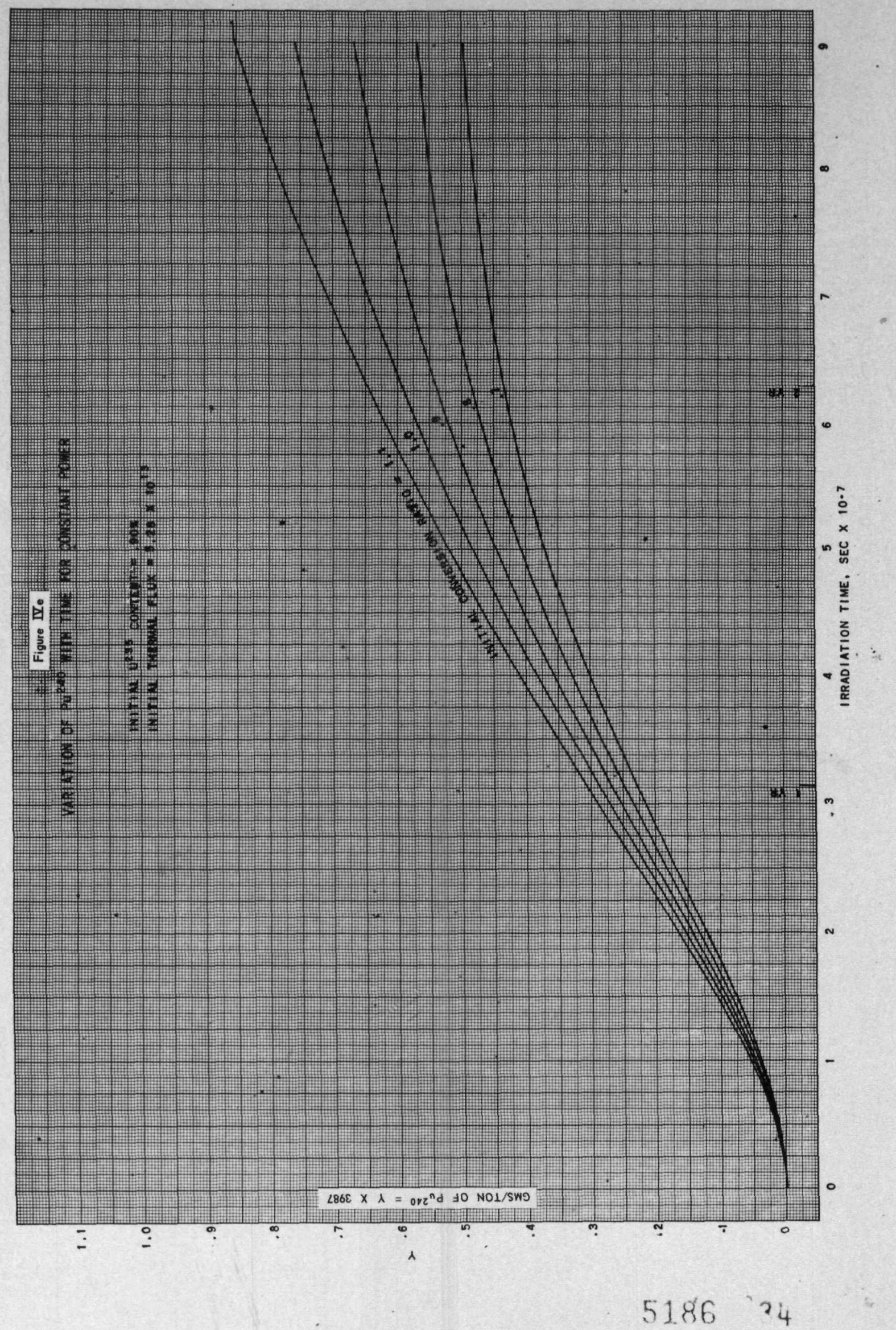




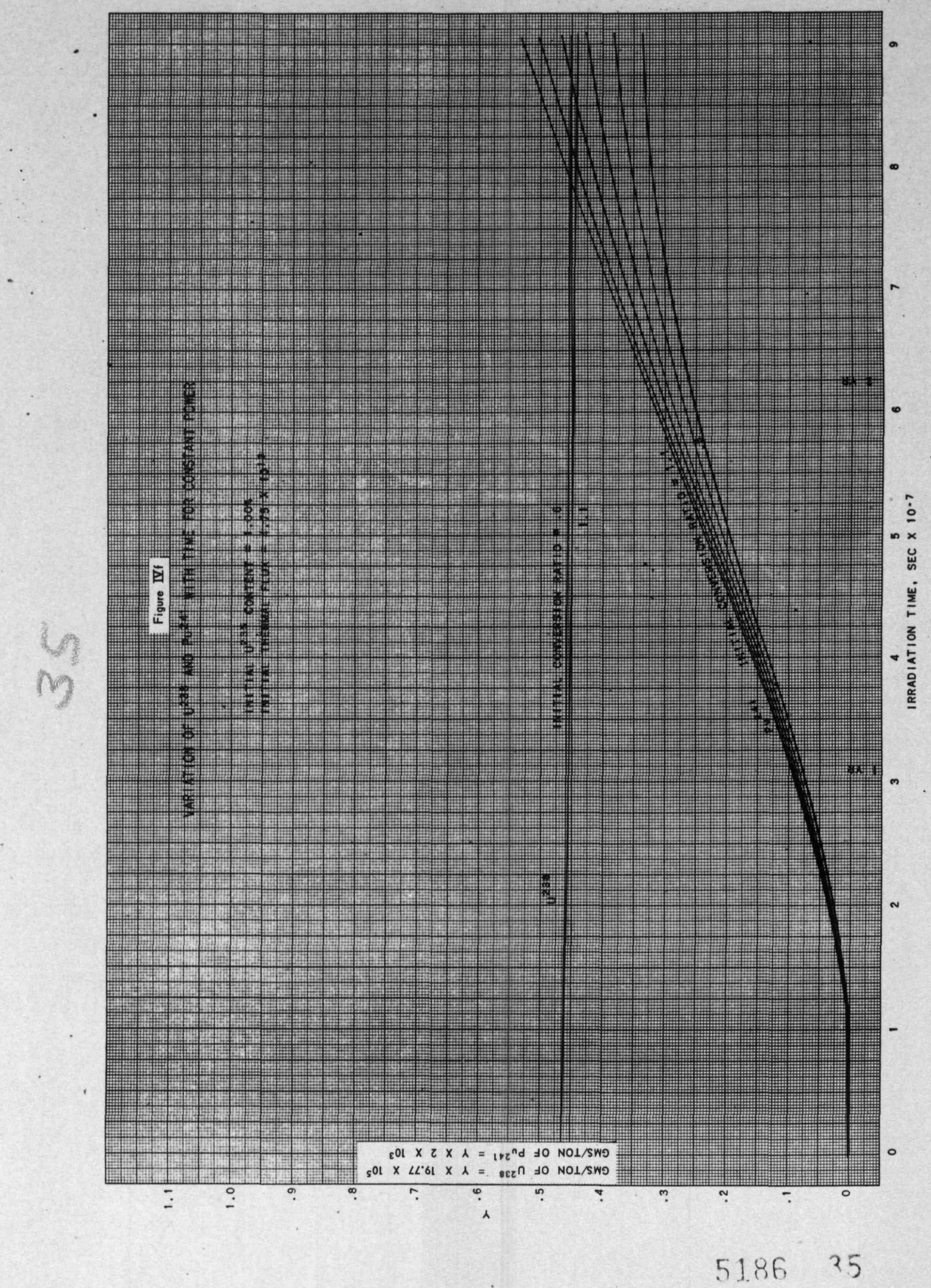




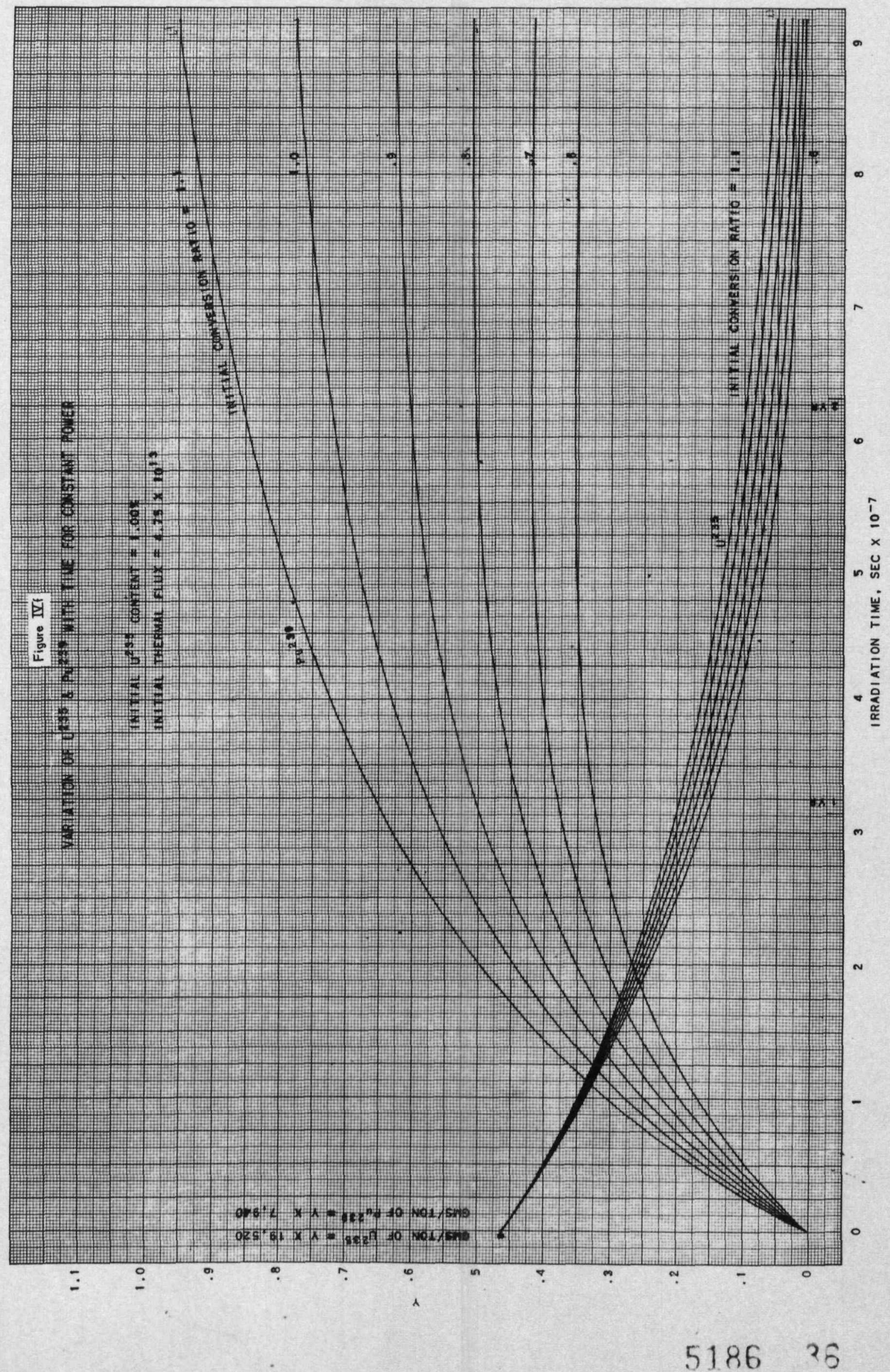




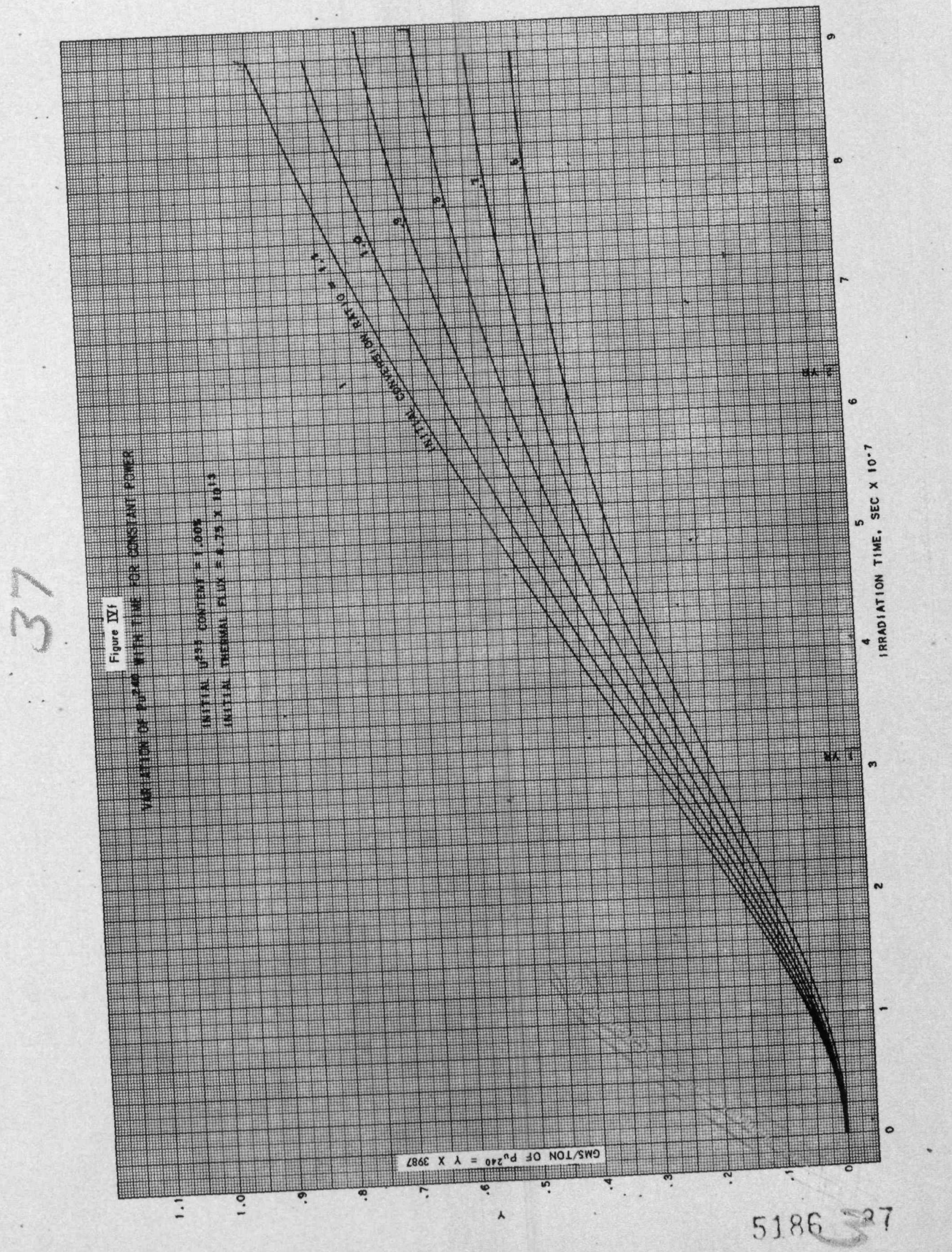




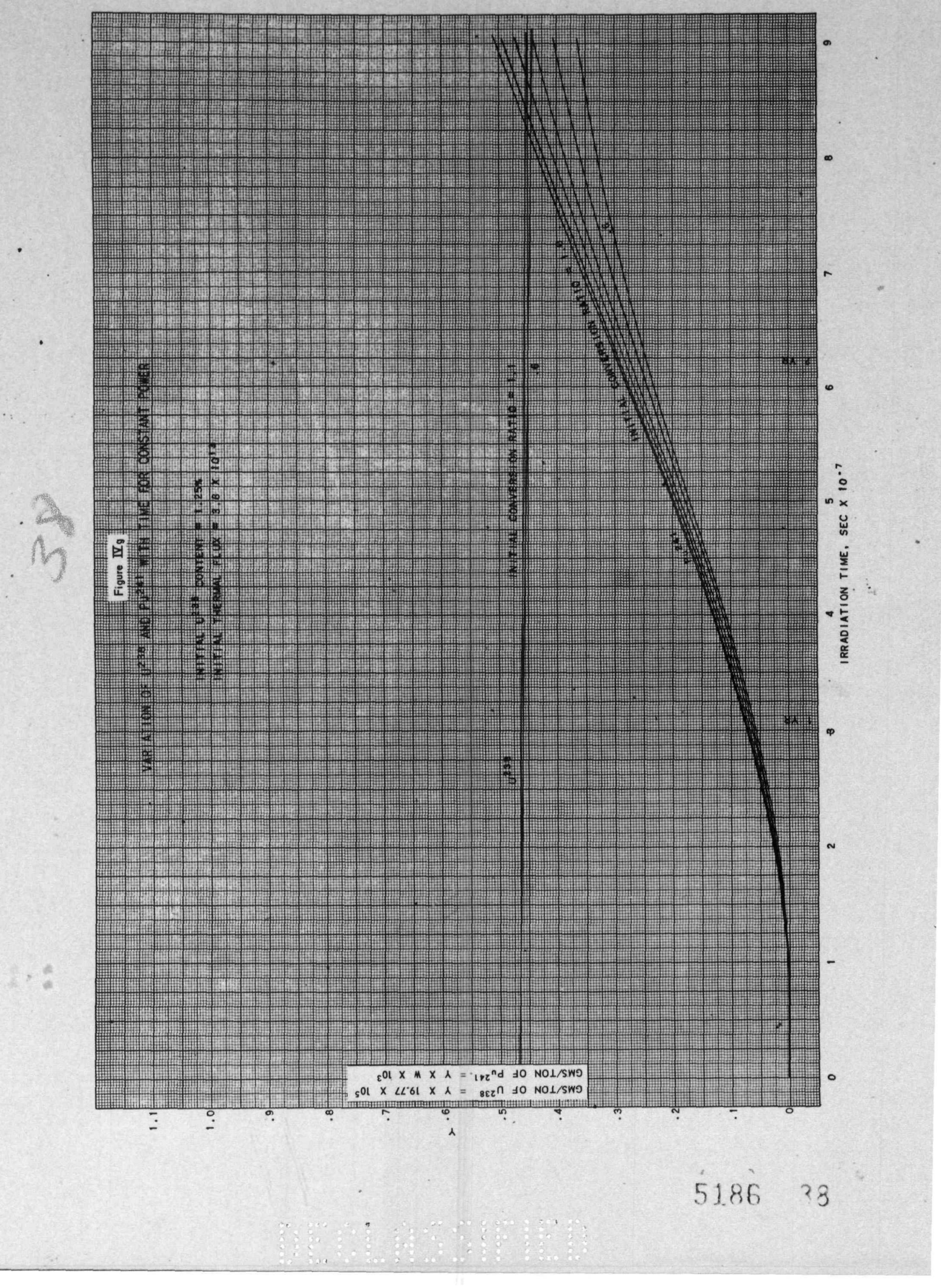




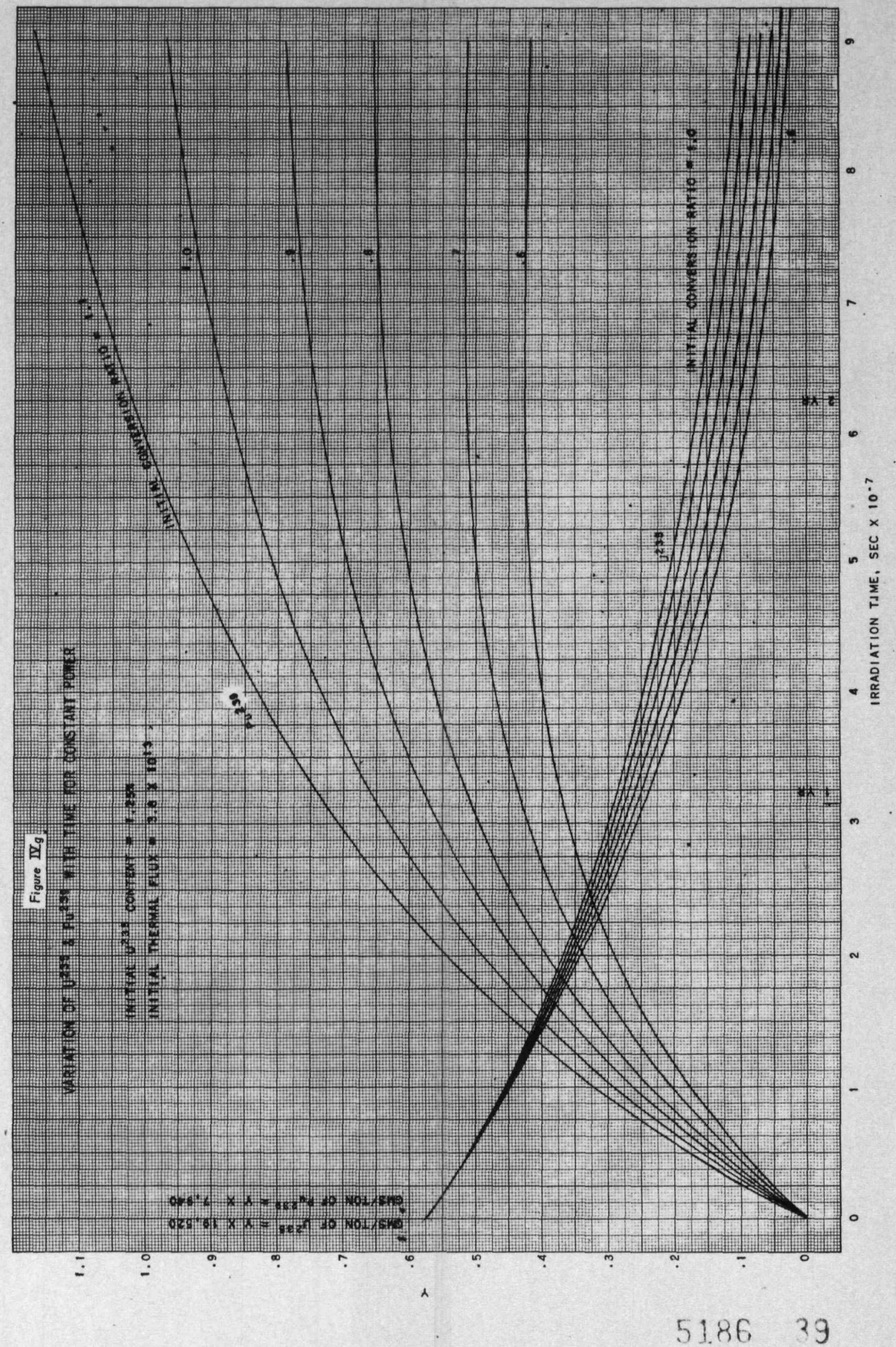




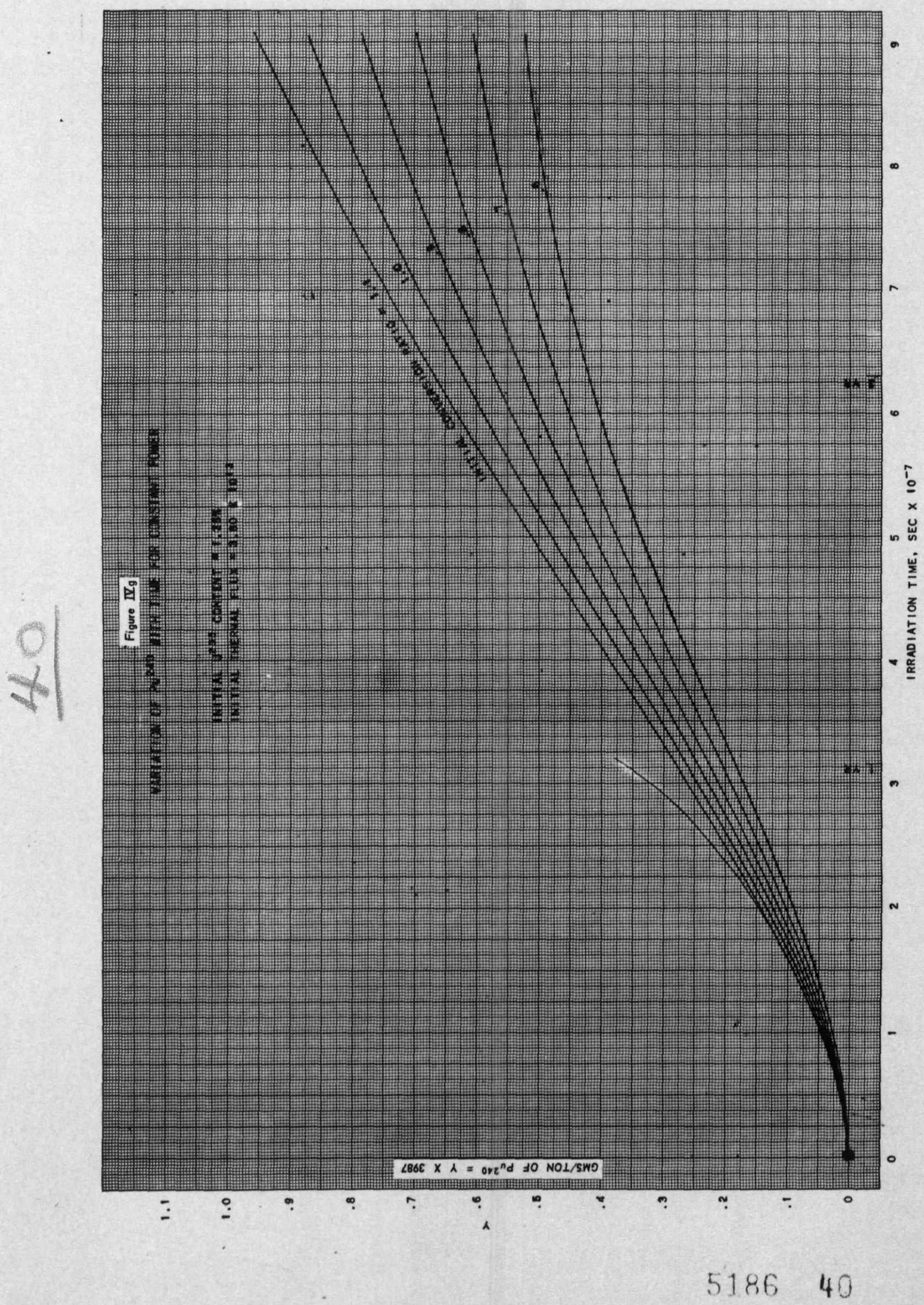




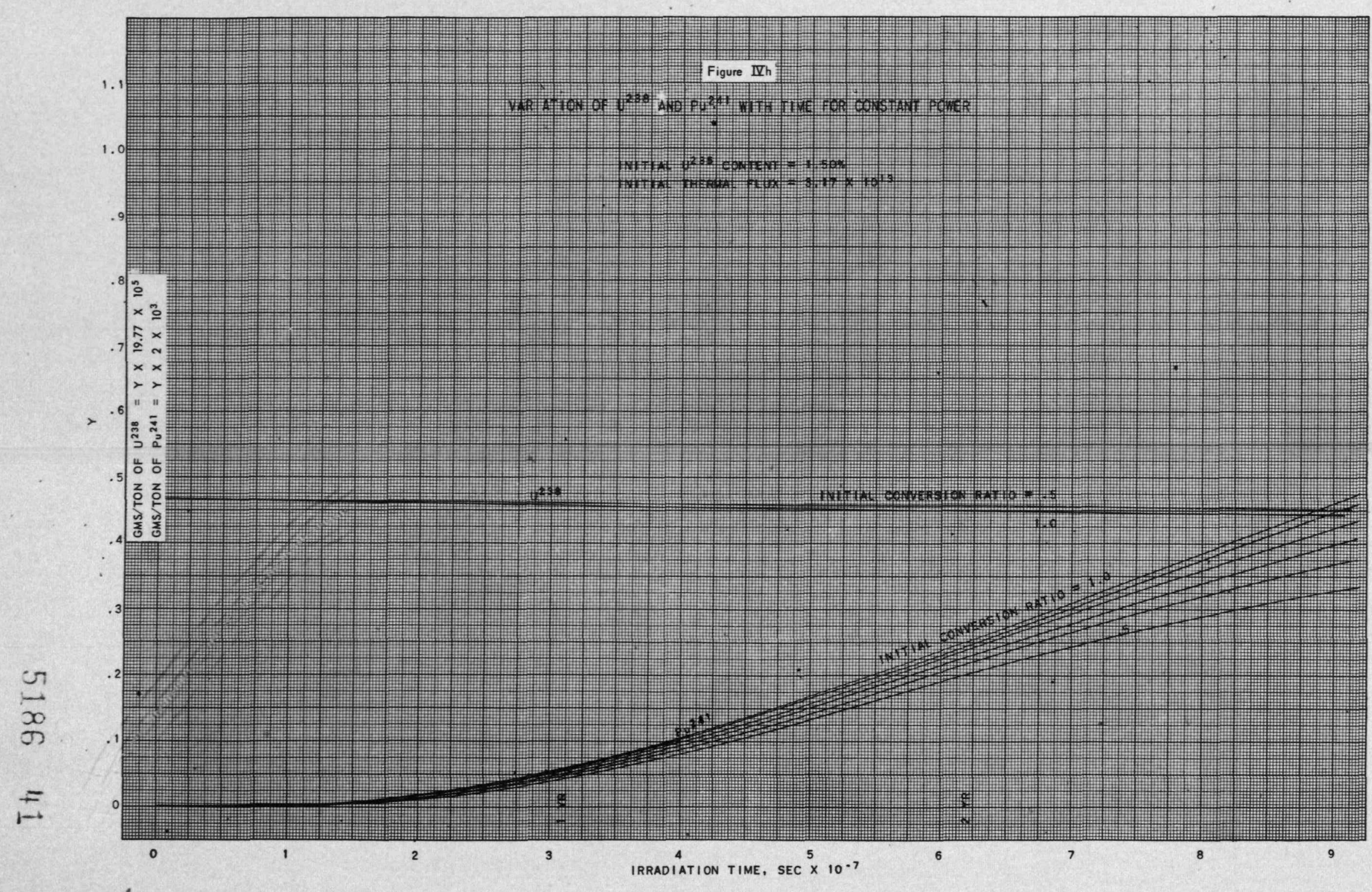



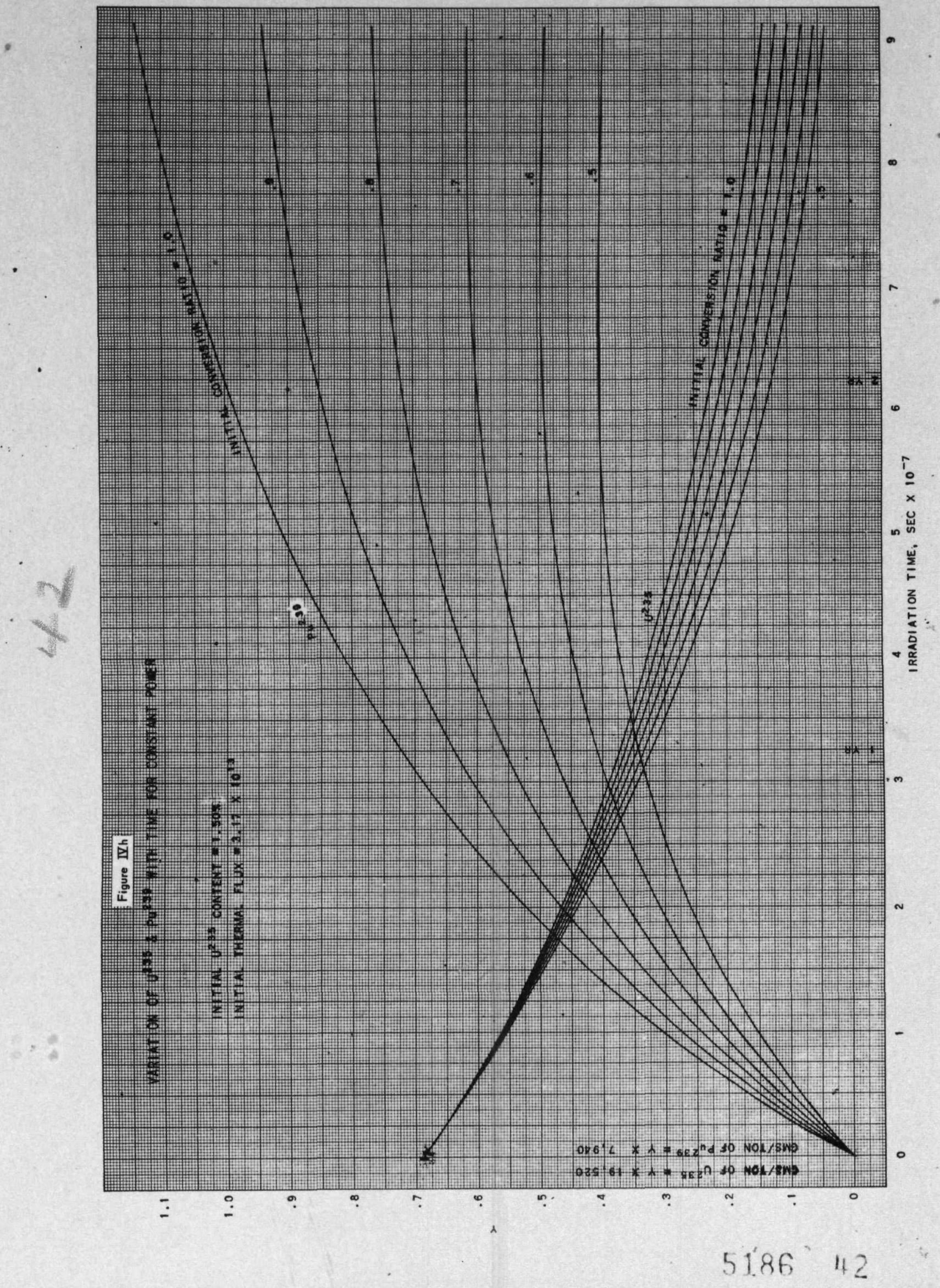


$$
43
$$

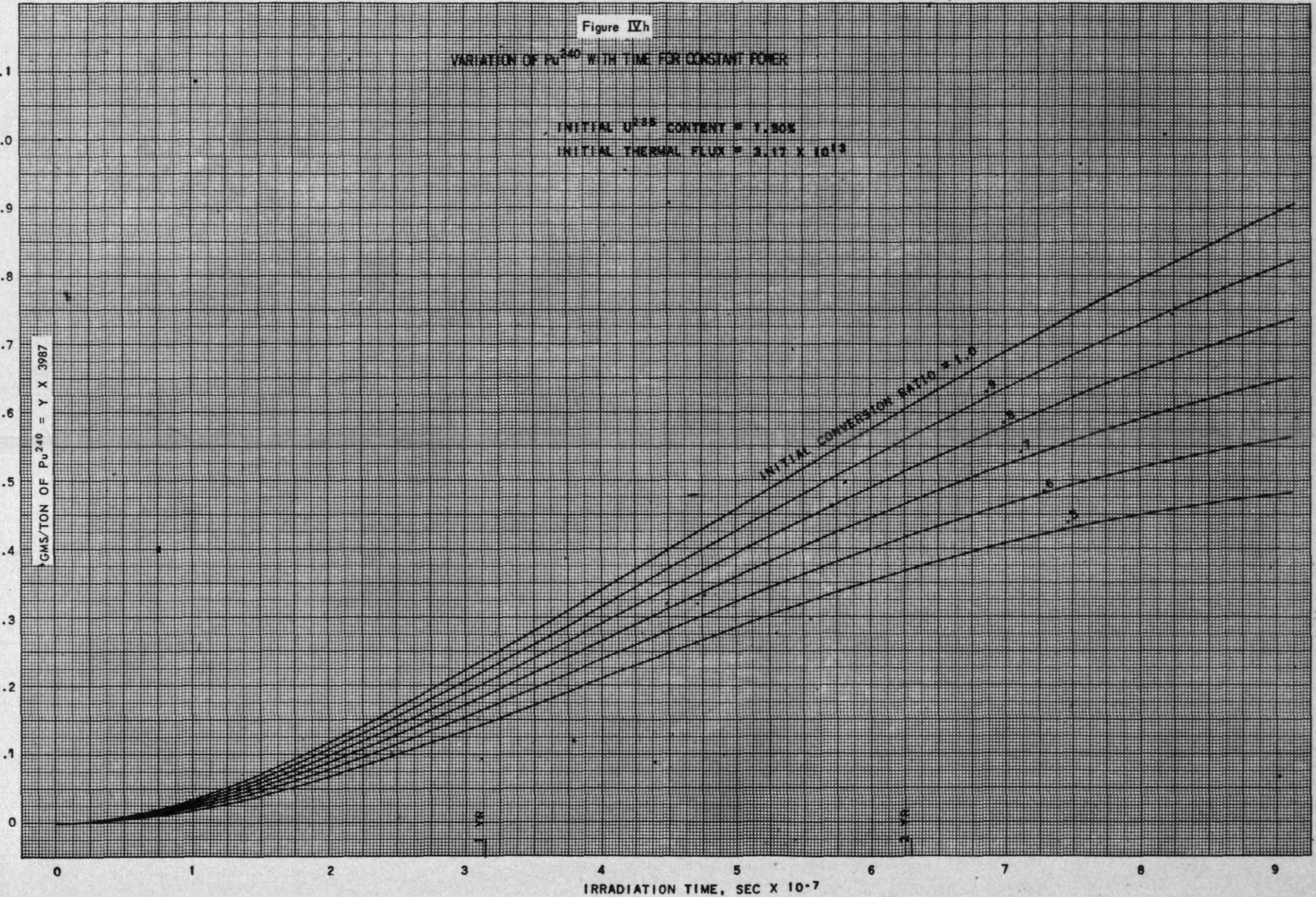




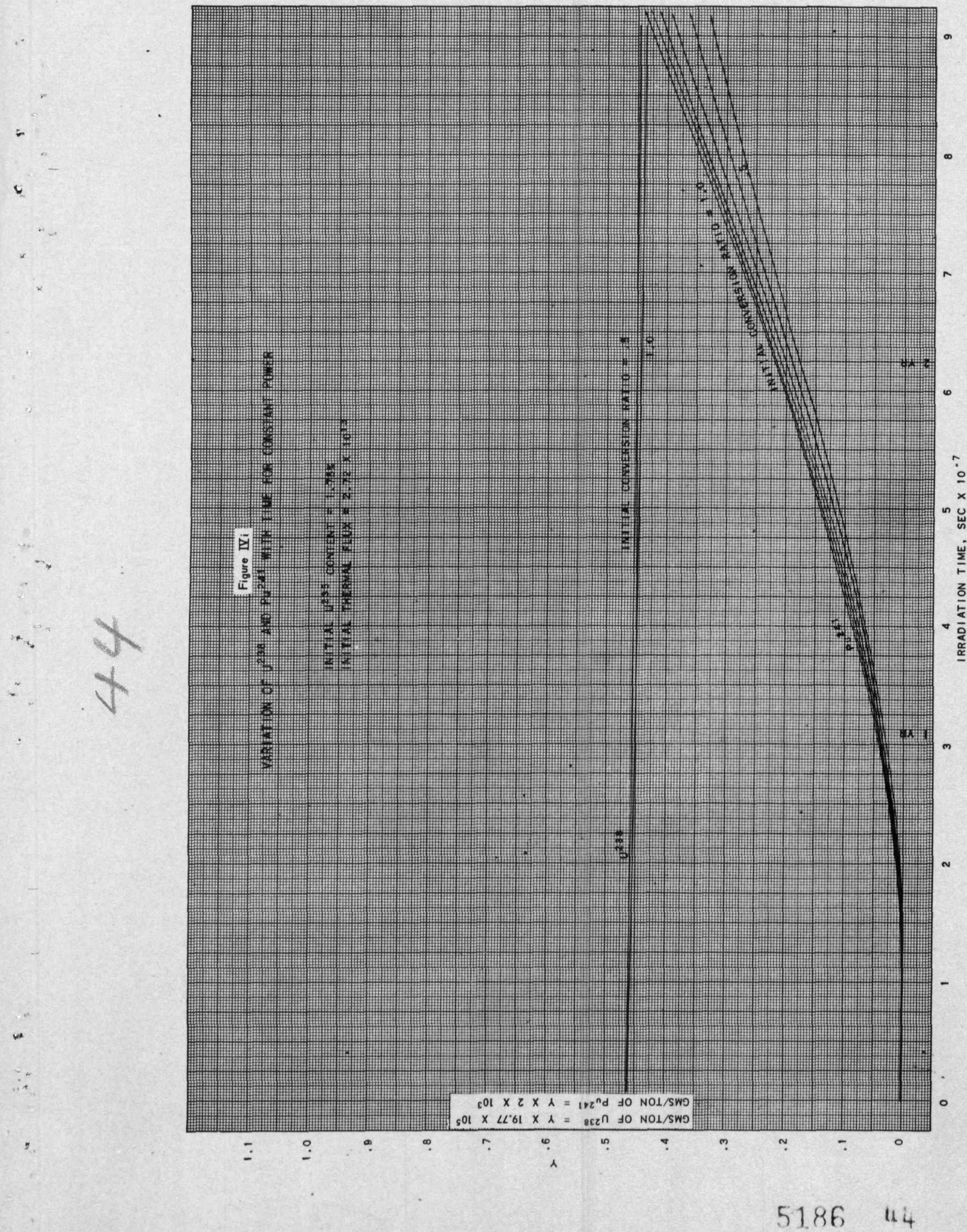




\section{5.}

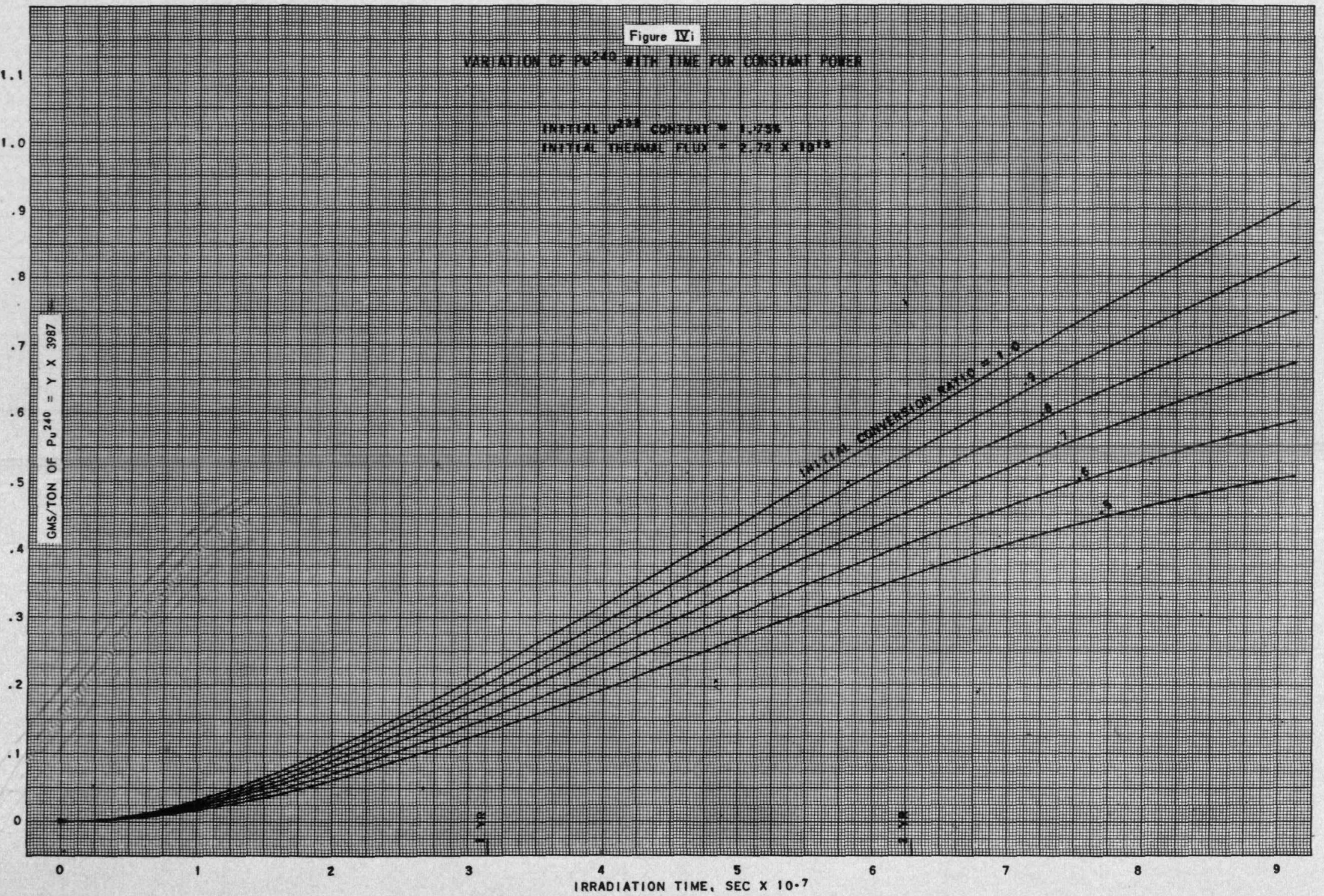




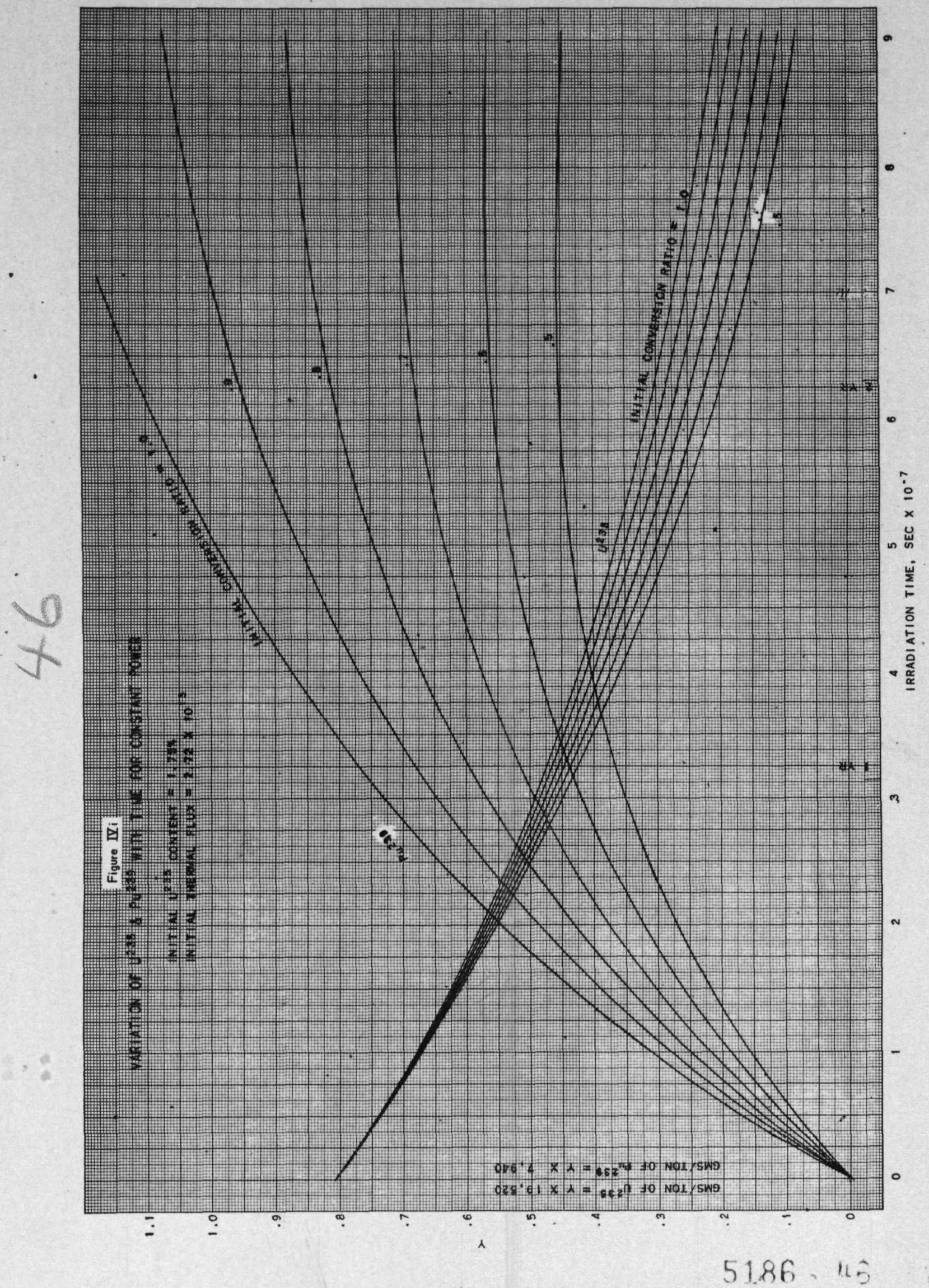




\section{7}

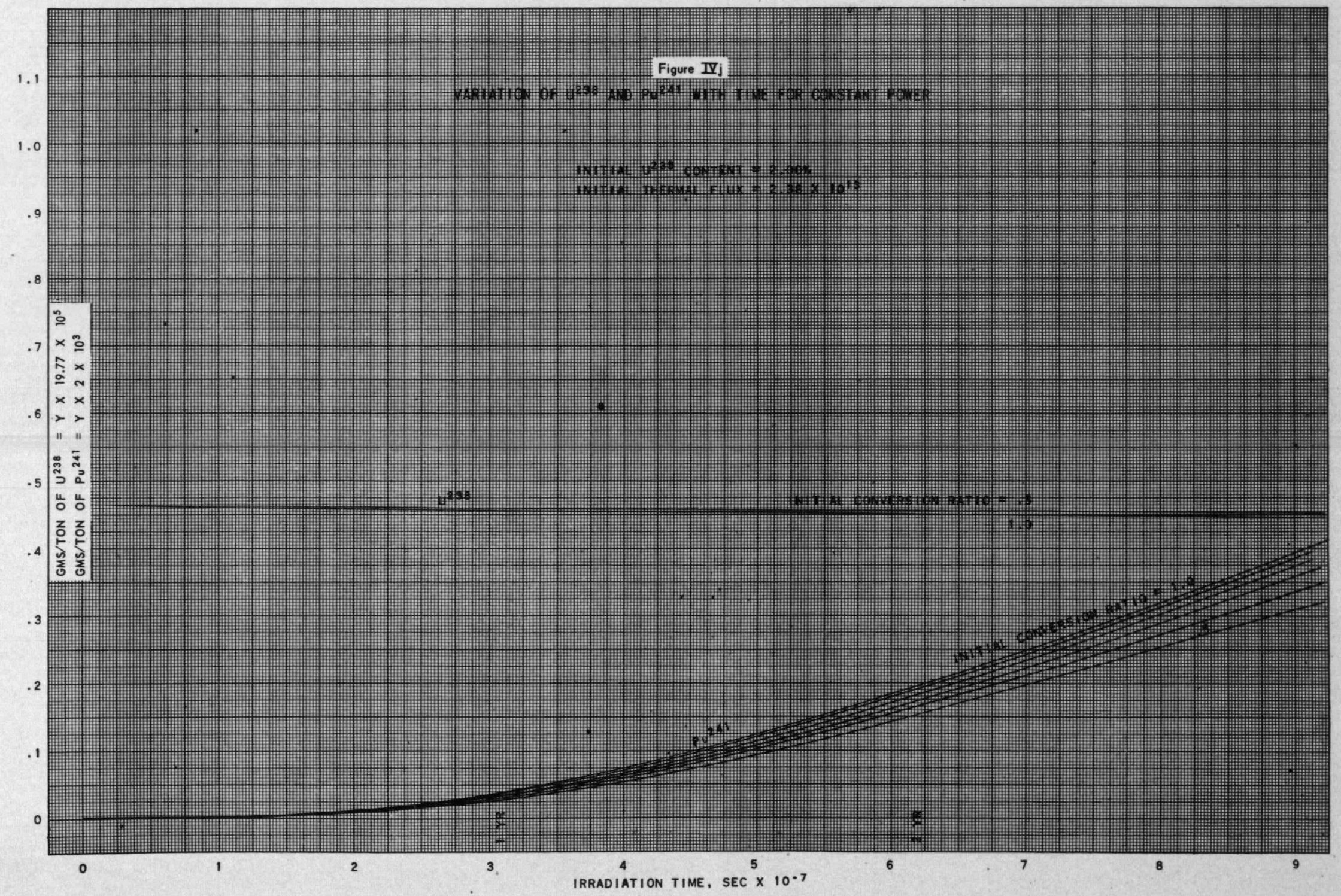




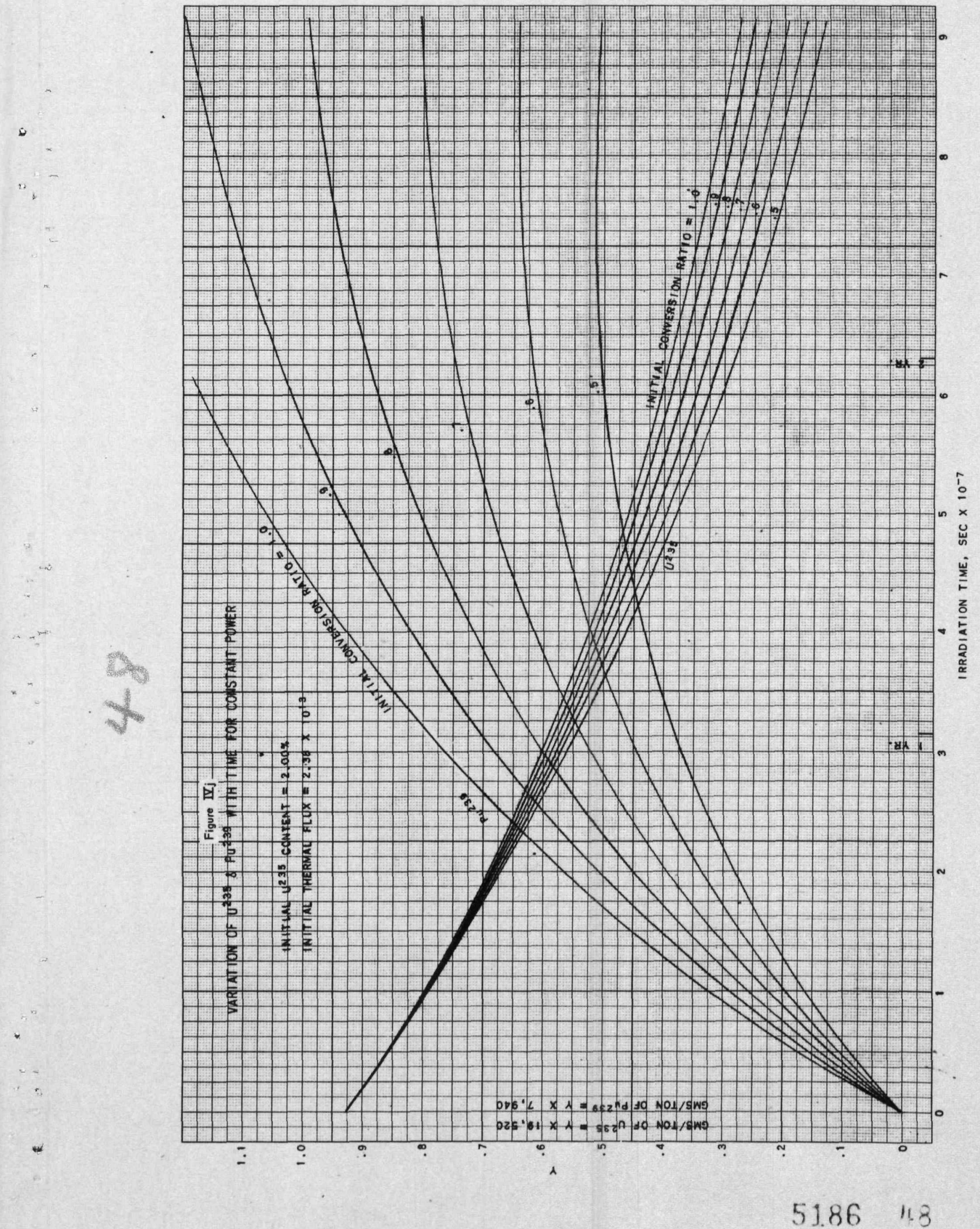




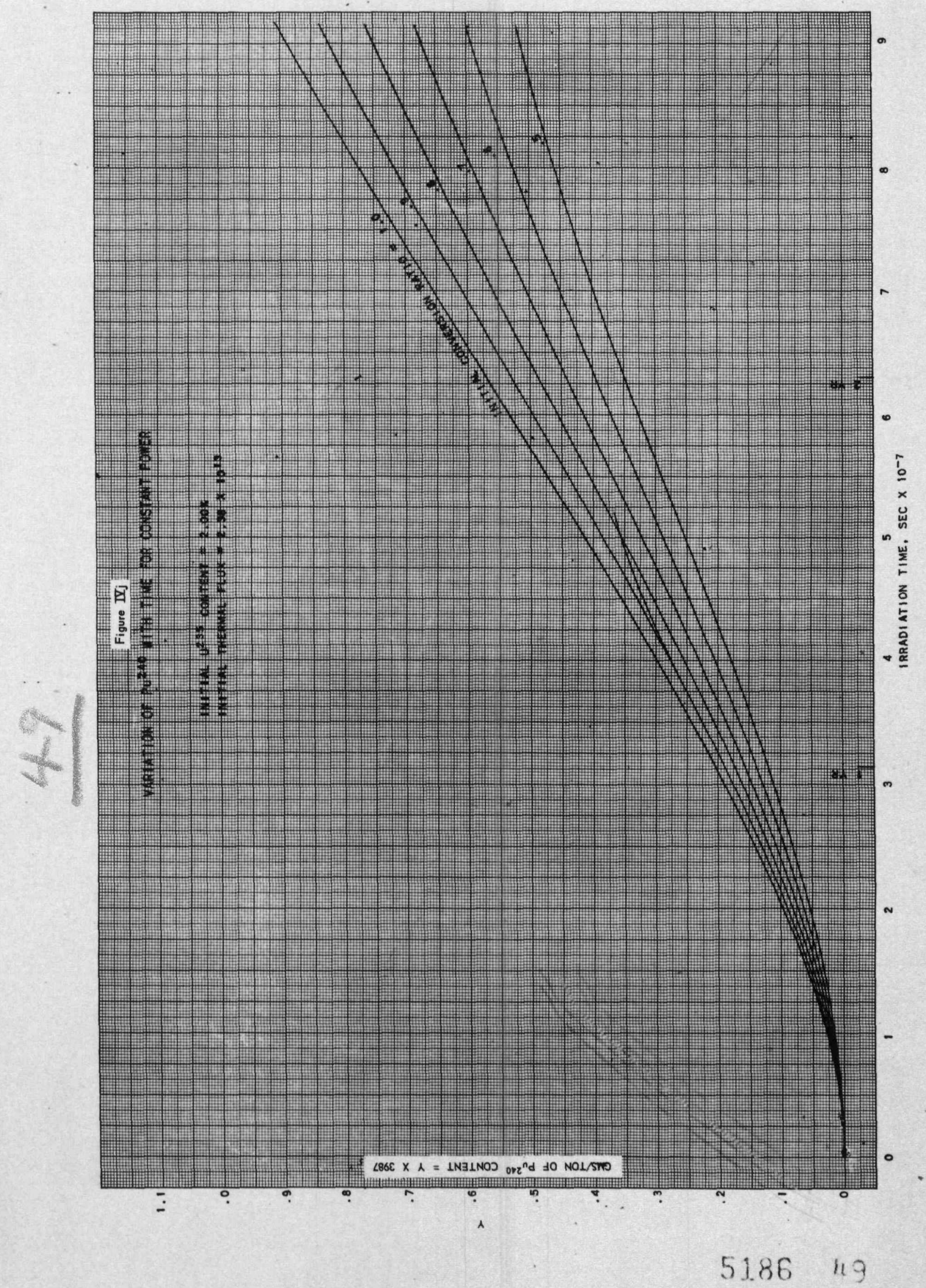




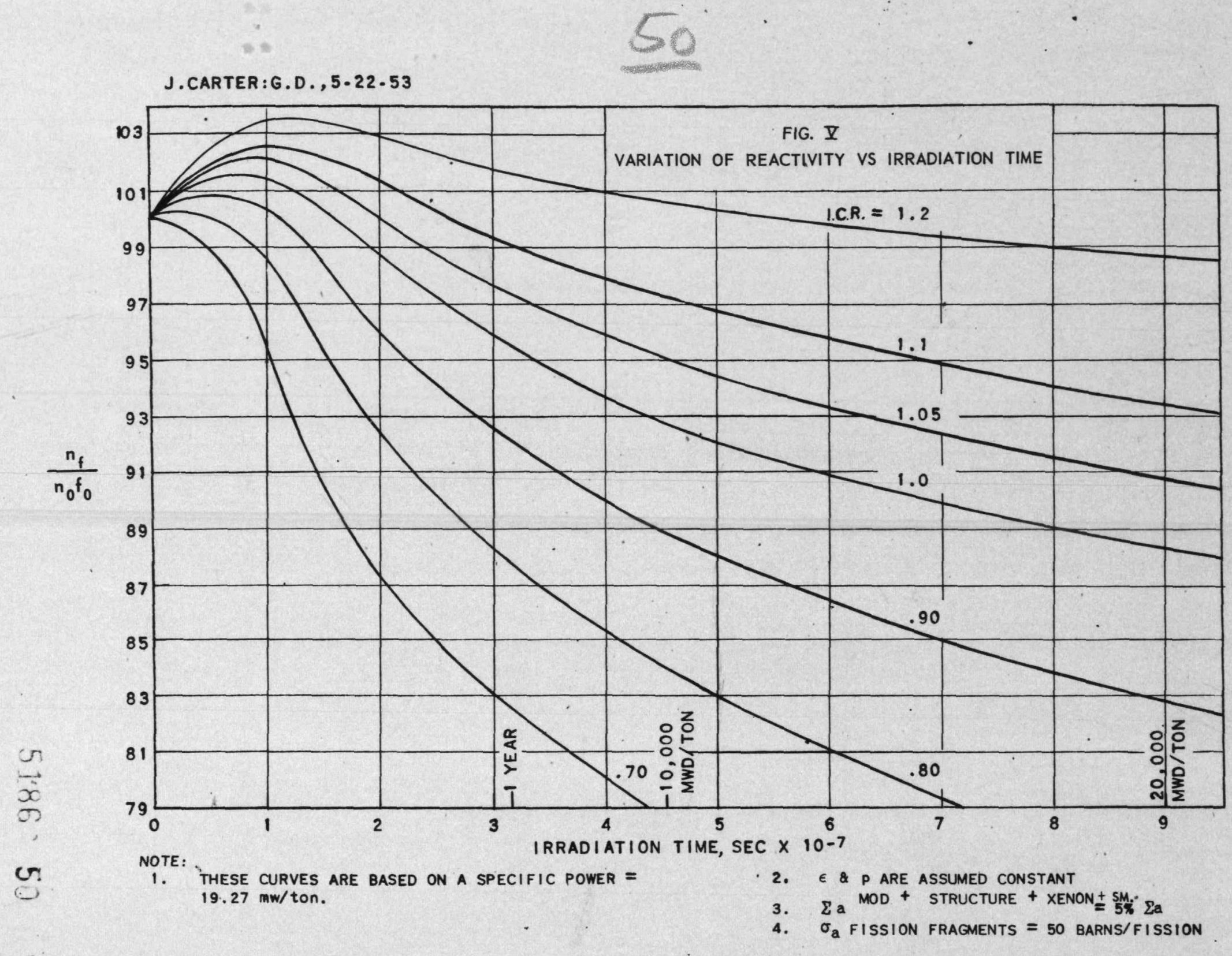

RE-7-11006-A 


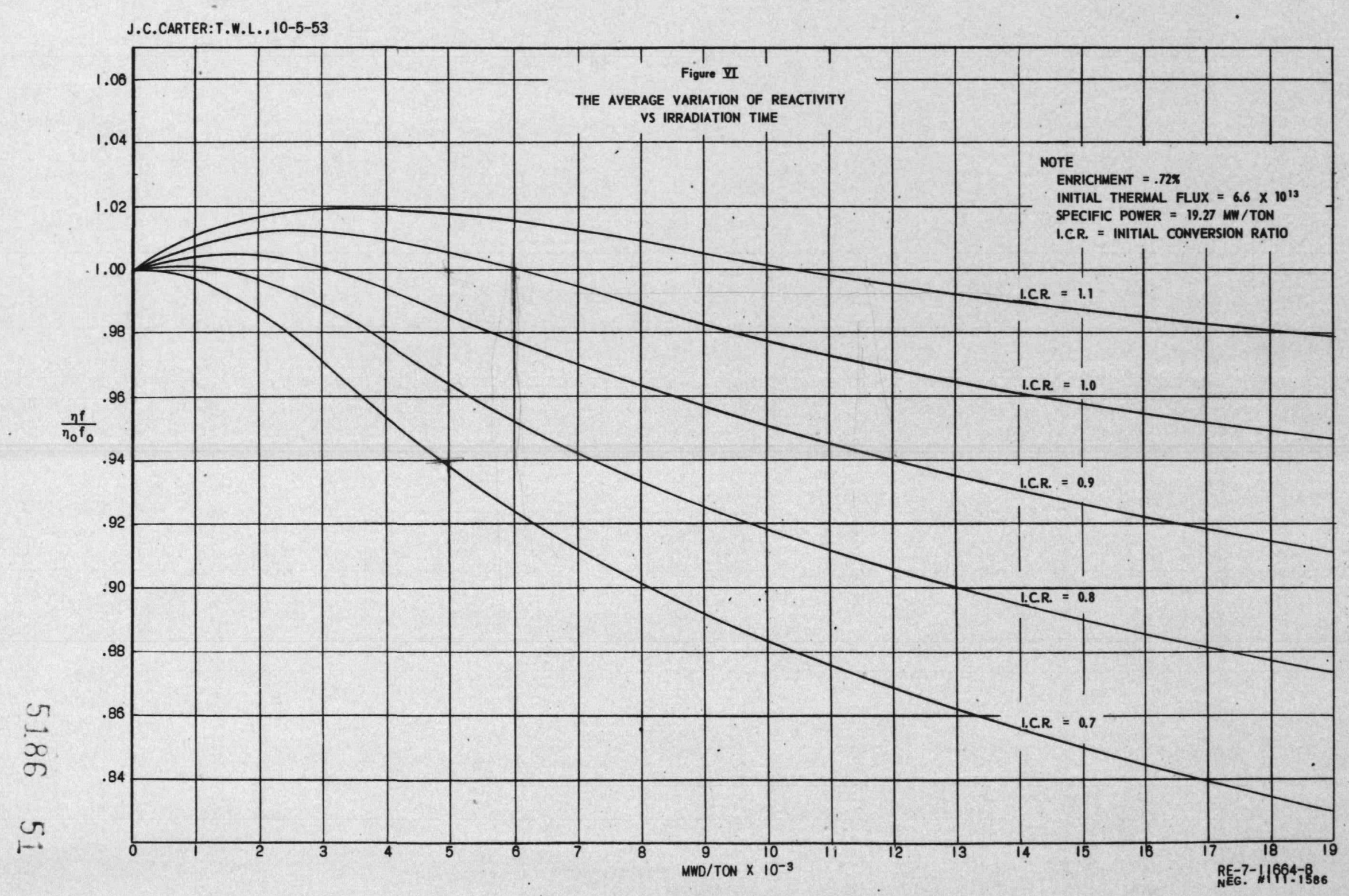




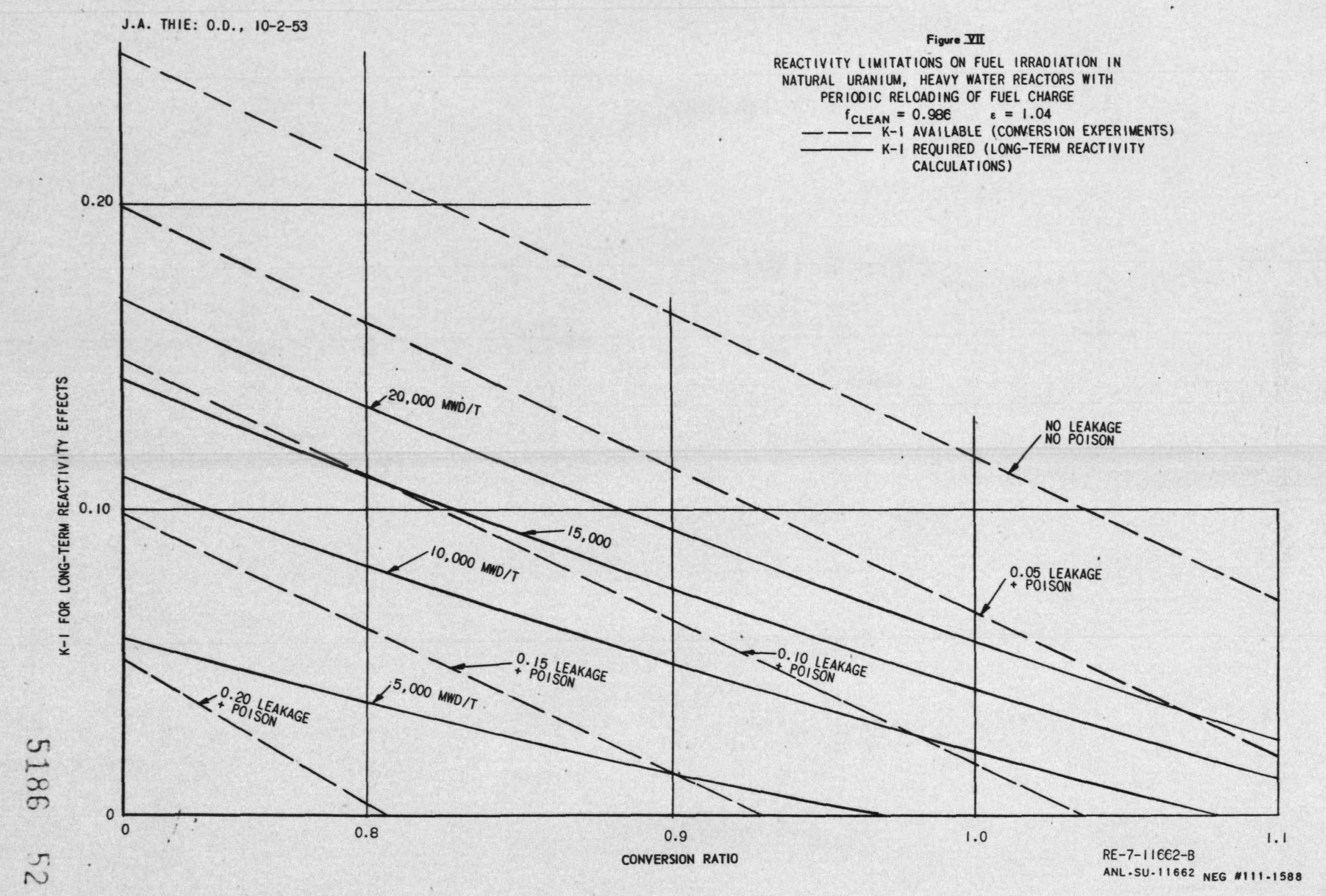


Es 98 is

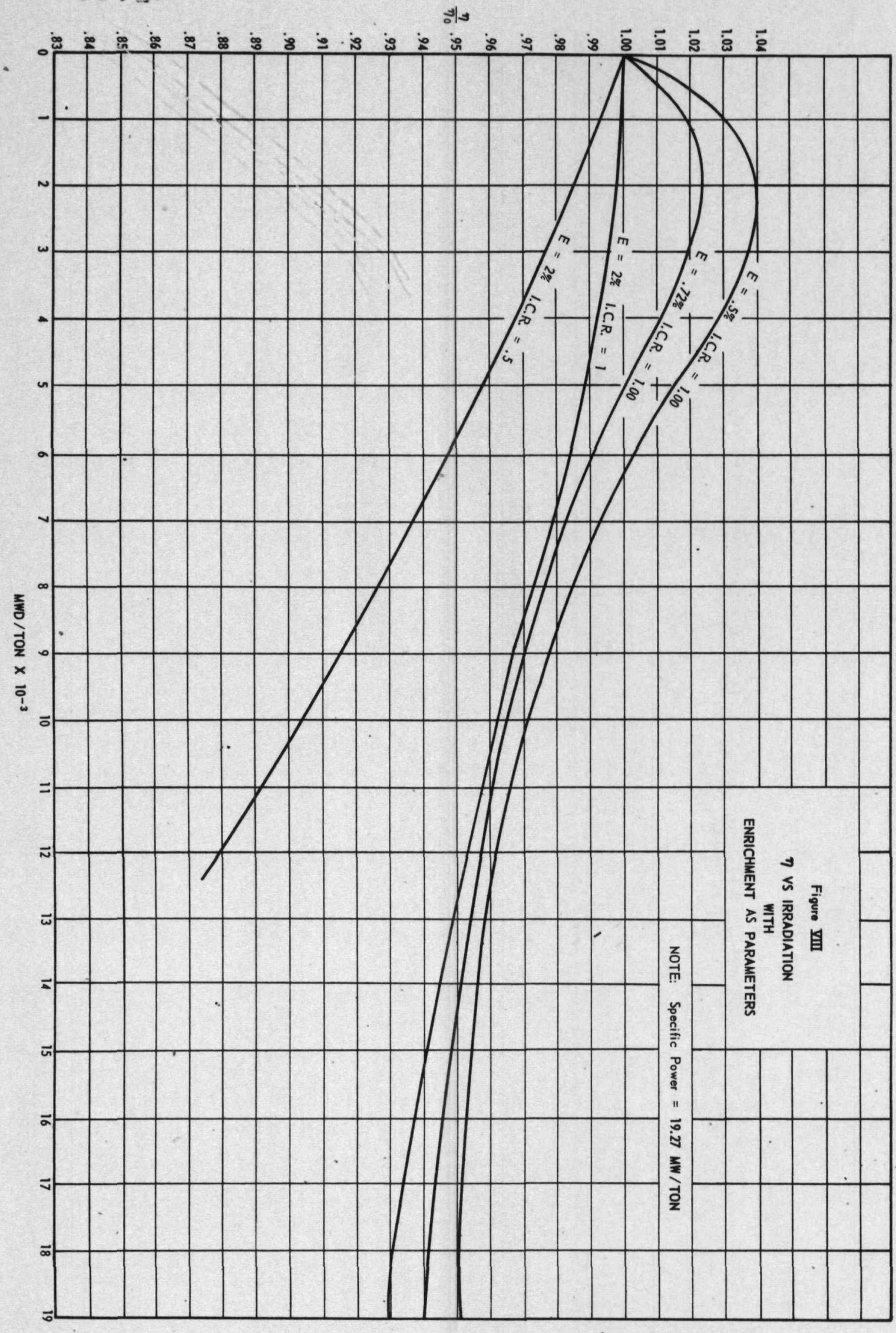




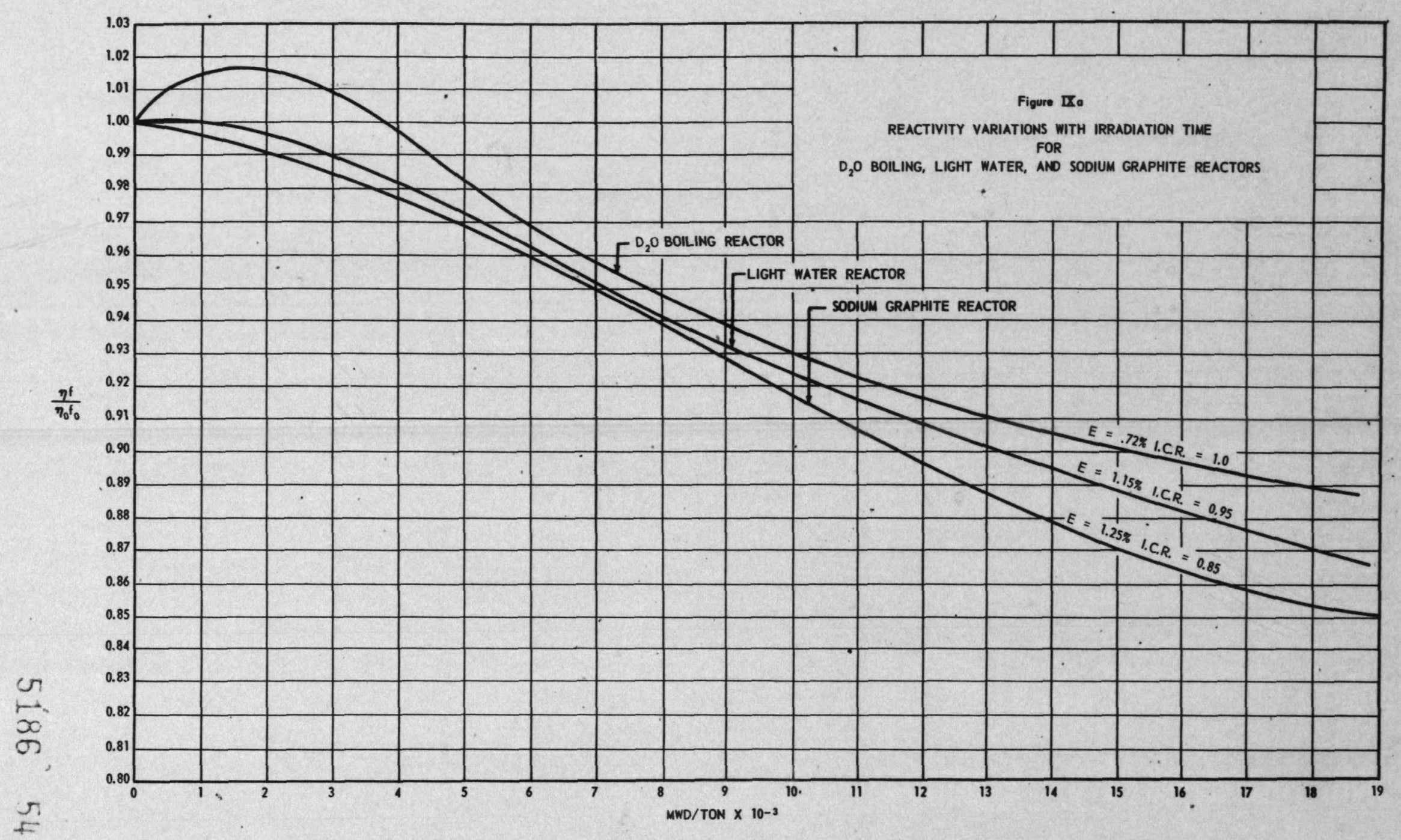

II 


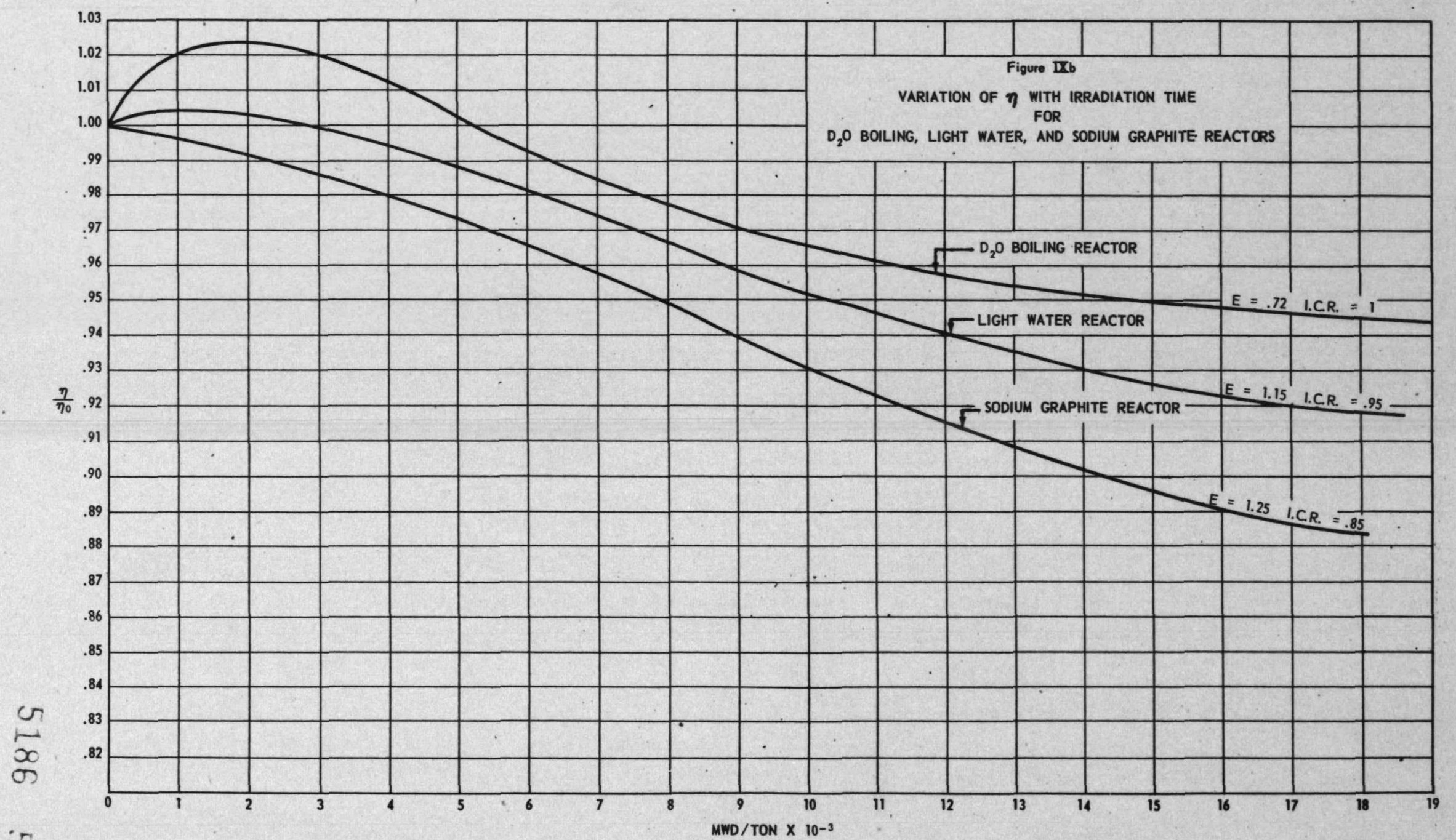

$$
\text { v }
$$




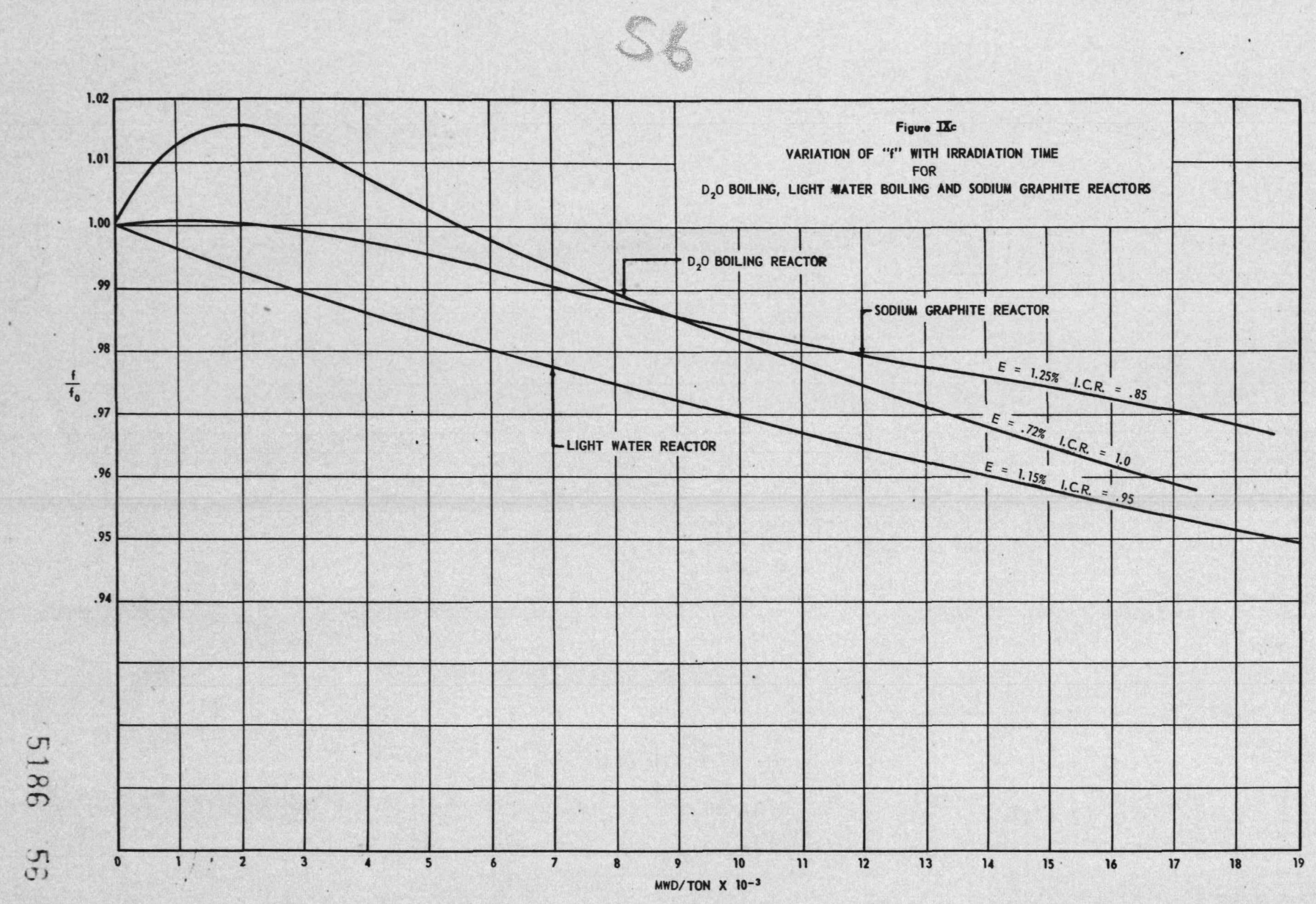




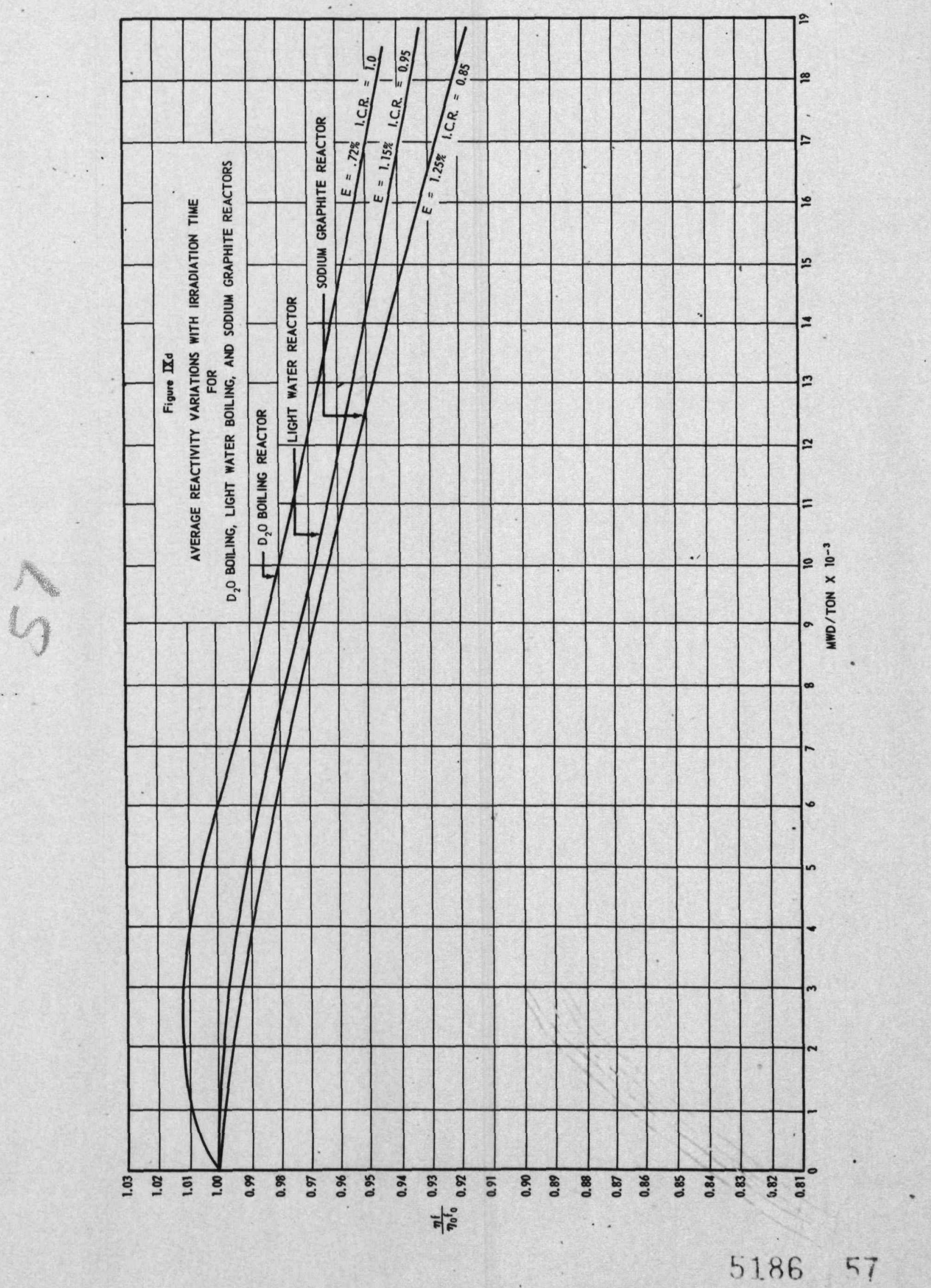



J.CARTER:H.G.S., ,9-11-53

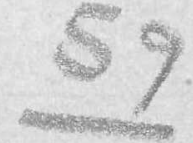

Figure XI

THE EFFECT OF REMOVING FUEL DURING THE OPERATION OF A NATURAL URANIUM REACTOR

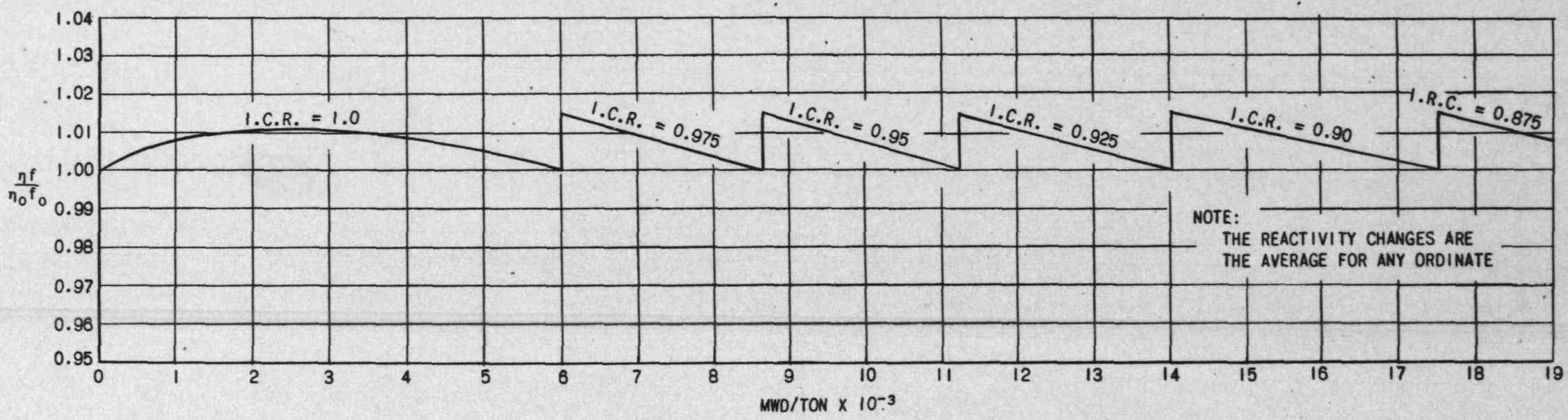

RE-7-11619-8

5
5
5
5 